\title{
Challenges for drought mitigation in Africa: the potential use of geospatial data and drought information systems
}

Sergio M. Vicente-Serrano ${ }^{1, *}$, Santiago Beguería ${ }^{2}$, Luis Gimeno ${ }^{3}$, Lars Eklundh ${ }^{4}$, Gregory Giuliani ${ }^{5}$, Derek Weston ${ }^{6}$, Ahmed El Kenawy ${ }^{7}$, Juan I. López-Moreno ${ }^{1}$, Raquel Nieto $^{3}$, Tenalem Ayenew ${ }^{8}$, Diawoye Konte ${ }^{9}$, Jonas Ardö ${ }^{4}$ and Geoffrey G.S. Pegram ${ }^{10}$

Instituto Pirenaico de Ecología, CSIC (Spanish National Research Council), Campus de Aula Dei, P.O. Box 202, Zaragoza 50080, Spain

2) Estación Experimental de Aula Dei CSIC (Spanish National Research Council), Zaragoza, Spain.

3) Environmental Physics Laboratory, Universidade de Vigo, Ourense, Spain

4) Department of Earth and Ecosystem Sciences, Division of Physical Geography and Ecosystems Analysis, Lund University, Lund, Sweden.

5) Institute for Environmental Sciences, University of Geneva, Geneva, Switzerland

6) Pegasys Strategy \& Development, Pretoria, South Africa

7) Department of Geography, University of Mansoura, Mansoura, Egypt.

8) Geology and Geophysics Department, Addis Ababa University, Addis Ababa, Ethiopia

9) Institut du Sahel (INSAH), Mali

10) School of Civil Engineering, University of KwaZulu Natal, Durban, South Africa

*svicen@ipe.csic.es 


\section{Challenges for drought mitigation in Africa: the potential use of geospatial data and drought information systems}

Abstract Understanding, monitoring and mitigating drought is a very difficult task as a consequence of the intrinsic nature of the phenomenon. In addition, assessing the impact of drought on ecosystems and societies is also a complex task, because the same drought severity may have different consequences in different regions and systems due to the underlying vulnerabilities. New technologies based on geospatial information are available to determine the risk and vulnerability of a system to a drought and to develop monitoring and early warning systems based on real-time information to support decision making. To improve drought preparedness and mitigation, geospatial datasets based on climate information, Earth Observation Systems and statistical and dynamical modeling methodologies can make a noticeably difference in mitigating drought impacts in Africa. In this article we illustrate how the development of drought information systems based on geospatial technology, that combines static and real-time information, could improve the possibilities of drought mitigation in Africa. We stress that it is necessary to go beyond past attempts to manage drought risk based on a reactive crisis-response approach, by promoting drought mitigation and preparedness at the national and regional levels. For this purpose the development of drought information tools is fundamental for the implementation of drought management plans and to support real-time decision-making.

Key-words: Drought, risk mitigation, drought indices, drought vulnerability, drought risk, capacity building, Standardized Precipitation Evapotranspiration Index, drought forecasting, Earth observation, NDVI.

\section{Introduction}


Drought is the natural hazard that affects a large number of people with the most negative consequences in Africa, being responsible for famine (Scrimshaw, 1987), epidemics and land degradation (UN, 2008; Bandyopadhyay et al., 2012). Among the most important natural disasters affecting the world, the two with highest number killed between 1974 and 2007, were the droughts that killed 450,000 and 325,000 persons in 1984 and 1974 in Ethiopia/Sudan and the Sahel region, respectively (UN, 2008). At present, a severe drought in 2011 in Somalia has caused a very important humanitarian crisis, with 10 million people needing humanitarian aid, more than 2 million children malnourished and in need of lifesaving action, and more than 380,000 refugees living in camps of Kenya (United Nations News Centre, http://www.un.org/apps/news/story.asp?NewsID=39077).

Droughts and floods account for $80 \%$ of loss of life and $70 \%$ of economic losses linked to natural hazards in Sub-Saharan Africa (Bhavnani et al., 2008). Persistent drought conditions are found to be the most significant climate influence on GDP per capita growth in Africa (Brown et al., 2011). The drought of 1990/1991 in Zimbabwe resulted in a GDP drop of 11 percent. Similarly, in Kenya the drought of 1999-2001 costs the economy some 2.5 billion dollars. As a proportion of the national economy this is a very significant loss and can be thought of as resources of foregone development (UN, 2008). These numbers naively summarize the great impact of drought in Africa, but the numbers commonly do not count for drought-related environmental damage and irreversible degradation, which can be the root of future impoverishment and resource depletion. In addition, the indirect effects of drought on household welfare through the impact on crop and livestock prices may be larger than the direct production effects of drought (Holden and Shiferaw, 2004).

Drought increases the structural problems of the African continent and in the last decades has caused a decrease of crop yields, unemployment, impoverishment and even forced migrations (UN, 2008; Bhavnani et al., 2008; Scheffran et al., 2012). The problem may increase in the future since the current population projections predict a demographic increase in the regions affected by chronic 
water deficits in Africa, and climate change models also indicate the likely increase of drought severity during the $21^{\text {st }}$ century (Dai, 2011), which are likely to increase famine (Jankowska et al., 2012) social conflicts and the risk of civil wars in African countries (Burke et al., 2009).

Various international organisations consider the development of actions to reduce drought impacts in Africa as a priority. The program: Millennium Development Goals (http://www.undp.org/mdg/basics.shtml) includes drought impact in goals 1 (Eradicate extreme poverty and hunger), 4 (Reduce child mortality) and 7 (Ensure environmental sustainability), since drought is in the root of most of these problems in developing African countries. The Food and Agricultural Organization of the United Nations (FAO) emergencies program has a particular concern in Africa and develops regional coordinate actions to guarantee the emergency aid, also considering the regional specific ecological and agricultural drought impacts. Drought in Africa is also one of the priorities of the European Commission Humanitarian Aid program (ECHO). For example, in September 2009 the Commission allocated a further 53 million Euros in humanitarian aid for drought response in several sub-Saharan countries recently affected by drought (Somalia, Kenya, Uganda, etc.) through the Commission's Humanitarian Aid department to provide basic food, nutritional support, protection of livestock assets and other forms of short-term livelihood support. These actions are commonly implemented by non-governmental relief organizations, specialized UN agencies and the Red Cross/Red Crescent.

Most of these actions belong to the response and recovery phases of the disaster management cycle (Figure 1), i.e. they are focused on alleviating the immediate effects of drought once the phenomenon has occurred and restoring the affected areas to their previous state (Wilhite and Svoboda, 2000). This is achieved by measures such as emergency water and food supply, subsidies, etc. These measures are very necessary from a humanitarian point of view, but are of limited effect in the long term since they can only cope with specific catastrophes; i.e., they hardly contribute to reducing the vulnerability of the affected societies to drought. In order to reduce the drought 
vulnerability of the affected societies, it is necessary to promote an integral conception of drought risk management (Wilhite, 1996). Hence, event-oriented actions need to be complemented by other measures focused on promoting drought risk mitigation and preparedness (Wilhite, 2002). Risk mitigation refers to long-term measures for reducing the risk such as the development of technological solutions, legislation, land-use planning, insurance, etc. Fundamental to risk mitigation is a thorough identification of risks and promotion of the risk perception. Preparedness refers to the development of emergency plans and warning systems for acting once the disaster strikes, or even to anticipate it.

Two fundamental requisites for reinforcing drought mitigation and preparedness in the long term are: i) an accurate drought risk assessment quantifying the degree of hazard and the vulnerability of the different regions; and ii) real-time information concerns the development of drought conditions and providing forecasts of the likely evolution of the drought. This was acknowledged by the World Summit on Sustainable development (24 Aug to 2 Sep 2002) by the UN and the Johannesburg Plan of Implementation of the Agenda 21

http://www.un.org/esa/sustdev/documents/WSSD_POI_PD/English/WSSD_PlanImpl.pdf), who pointed to priority policy actions which included “...(e) Providing affordable local access to information to improve monitoring and early warning related to desertification and drought." The Review of implementation of Agenda 21 and the Johannesburg Plan of Implementation by the Commission on Sustainable Development of the UN Economic and Social Council (5-16 May 2008) stressed that "the establishment and effective operation of systems and networks for drought monitoring, early warning and drought impact assessment are essential to the identification and formulation of effective and timely response actions".

New technologies based on geospatial information are available to determine the risk and vulnerability of a system to a drought and to develop monitoring and early warning systems based on real-time information to support decision making (Svoboda et al., 2002; Carbone et al., 2008). In 
developed countries, drought monitoring and early warning systems are very efficient in helping the process of drought risk mitigation. The Drought Monitor run by the US's National Drought Mitigation Centre the U.S. and the drought monitoring system of the Bureau of Meteorology of the Australian Government are excellent examples.

Some efforts to establish regional drought monitoring systems in Africa include the Regional Early Warning System of the Southern African Development Community (SADC), the Drought Monitoring Centre for the Great Horn of Africa (GHA) and the West African Permanent Interstate Committee on Drought Control in the Sahel (CILSS). These systems focus on selected droughtprone areas, but they do not cover the entire African continent. And more importantly, the systems are not operative in real-time and in some cases are not updated regularly. The situation with respect to drought impact assessment, monitoring and early warning in most drought-prone regions in Africa, remains far from satisfactory. Despite the international efforts for improving drought management in Africa, the implementation of drought management plans at the national level is in a very early stage. Only in some drought prone regions such as the Sahel drought management protocols such as PREGEC (Projet de Gestion des Crises) have been developed and included as part of national security and prevention plans.

The Review of implementation of Agenda 21 and the Johannesburg Plan indicates that "many drought-affected developing countries are encountering difficulties in achieving effective integration of drought management plans within the national development and budgetary frameworks". The main constraints suggested for the lack of implementation are political and particularly the "weak institutional structures, lack of technical capacity, limited progress in mobilizing stakeholder participation and investment, and lack of in-depth understanding of the benefits of effective drought management for poverty reduction and economic development" and also the lack of a preparedness culture. This displays another crucial aspect of promoting drought risk management in Africa, which is the need for specific efforts to enhance risk perception, 
stakeholder participation, and in general capacity building at both technical and the political levels, linking the indigenous capacities and adaptation strategies to maintain rural livelihoods with various forms of institutional and/or external support (Batterbury and Warren, 2001; Barbier et al., 2009; Rodima-Taylor, 2012). Therefore, drought initiatives reacting to the problems in Africa caused by droughts, in an especially vulnerable continent, must contribute to enhance drought risk mitigation and preparedness. This should be achieved through policy-relevant actions focused on risk and vulnerability assessment and on the development of monitoring, early warning and forecasting systems, with emphasis on stakeholder participation and capacity building. To improve drought preparedness and mitigation, geospatial dataset based on climate information, Earth Observation Systems and statistical and dynamical modeling methodologies can make a noticeable contribution. In this article we illustrate how the development of drought information systems based on geospatial technology, that combines static and real-time information, could enhance drought mitigation in Africa.

\section{Geospatial data and technologies to improve drought preparedness and mitigation}

Drought is a natural phenomenon that occurs when water availability is significantly below normal levels over a long period and the supply cannot meet the existing demand (Havens, 1954; Redmond, 2002). Despite the apparent simplicity of this definition, as a consequence of the intrinsic nature of the phenomenon, understanding, monitoring and mitigating drought is a very difficult task. Due to its long-term development and duration, the progressive character of its impacts and diffuse spatial extent, drought is the most complex natural hazard to identify, analyze, monitor and manage (Burton et al., 1978; Wilhite, 1993). Drought conditions are much more difficult to identify than other natural hazards since drought is commonly the result of a number of factors, which are only apparent after a long period of precipitation deficit; it is very difficult to determine its onset, extent and end. In contrast to other natural hazards such as floods, which are typically restricted to small 
regions and well-defined temporal intervals, drought is difficult to pinpoint in time and space, affecting wide areas over long time periods (Vicente-Serrano et al., 2010). Moreover, it is very difficult to objectively quantify drought severity, as it is a combination of the duration, magnitude and spatial extent of the drought (Dracup et al., 1980).

A further difficult problem in analyzing drought is its multi-scalar nature, since the responses of the hydrological systems (soil moisture, groundwater, river discharge, reservoir storage, etc) and biological ones (crops, natural vegetation) to precipitation, vary markedly and have different response times (McKee et al., 1993; Vicente-Serrano and López-Moreno, 2005; Ji and Peters, 2003). Thus, the time scale over which water deficits accumulate becomes extremely important, and functionally separates between hydrological, environmental, agricultural and other types of drought (Wilhite and Glantz, 1985). This explains why severe drought conditions can be recorded in one system (e.g., low river flows) while another system (e.g., crops) presents normal or even humid conditions. Hence, it is necessary to develop a quantitative, objective and transparent method for characterizing the drought condition over a region and a variety of systems. Such a method should be operative both for analyzing historical droughts according to available data and for monitoring current drought conditions. Finally, although precipitation is the main variable to explain drought conditions, other parameters also play a role to explain drought severity, mainly temperature (via evapotranspiration processes). As a consequence of global warming a changing role of the drought determining factors is anticipated, so static approaches to drought assessment are not valid to identify drought hazard and vulnerability (e.g., Dubrovsky et al., 2008; Vicente-Serrano et al., 2010b; Dai, 2011).

Assessing the impact of drought on ecosystems and societies is also a complex task, because the same drought severity may have different consequences in different regions and systems due to the underlying vulnerabilities. Drought vulnerability is the limited ability of a system to cope with drought, and is determined by its resistance and resilience to water scarcity. Resistance refers to the 
capacity to anticipate, reduce or slow the drought impact, and resilience refers to the capacity to recover after a drought. A society and ecosystem well adapted to climate variability will be able to survive severe drought episodes without suffering irreversible degradation. In Africa however, population growth and overexploitation of the natural resources, the abandonment of traditional production systems and the development of economic and social structures reduce the ability to cope with changes and a generalized lack of adaptation to natural climate variability, including drought (Bruce, 1994; Nicholson et al., 1998; Antwi-Agyei et al., 2012). For these reasons the vulnerability of communities and ecosystems to drought risk has increased in Africa over the last decades, as evidenced by an increase of the costs attributable to drought (Obasi, 1994; CRED, 2011; Dinar and Keck, 2000).

Due to its diffuse spatial and temporal limits, multi-scalar and delayed impact, and to locally varying vulnerabilities, drought risk management is extremely complex. For these reasons, it is necessary to go beyond past attempts to manage drought risk based on a reactive crisis-response approach by promoting drought mitigation and preparedness at the national and regional levels. For this purpose the development of drought information tools is fundamental for the implementation of drought management plans and to support real-time decision-making.

Thus, drought mitigation actions and preparedness plans must be based on complete, transparent and integrated drought risk information. This should include geospatial information based on the analysis of past drought events in order to facilitate the elaboration of mitigation and preparedness plans, but also real-time information about the current drought conditions and their expected impacts in order to facilitate sound decision-making. Drought indicators based on climate data and remote sensing products are at present the best available tools to monitor drought over large regions and time periods. The use of multi-scaling drought indicators is necessary in order to address the drought impacts to a variety of ecosystems and societies (Vicente-Serrano and López-Moreno, 2005; Vicente-Serrano et al., 2010b, Lorenzo-Lacruz et al., 2010; Vicente-Serrano et al., 2011). In 
addition it is necessary to assess the degree of physical hazard in Africa by analyzing the historical data set of past drought events, as characterized by drought indicators. Drought hazard assessment must be expresses in terms of probability of occurrence of drought of varying severity and must be spatially explicit, i.e. must identify spatial differences in the degree of hazard. But integrated drought risk assessment must go beyond the mere calculation of the physical drought hazard and it must consider the vulnerability of the ecosystems and societies to drought. Vulnerability assessment can be done based on historical data of the systems exposed to drought, and must result in vulnerability curves indicating the expected impact on those systems of drought of varying severity. Thus early warning is only possible if such a combination of hazard and vulnerability assessments is made.

Moreover, real-time drought monitoring is indispensable to guarantee the operability of drought preparedness plans. Drought monitoring can be based on the drought indicators used for analyzing the drought events of the past, calculated using available sources of information on climatic data and satellite imagery. In addition the drought monitoring systems should include forecasting at the seasonal time scale since it is made possible, based on current Global Climate Models (Palmer et al., 2004), and should be included in any drought information system as part of the drought management tools.

Therefore, it is possible to use current geospatial information to implement drought information systems to serve as tools for planning and decision-making. Nevertheless, the assessment of the current institutional (formal and informal) setups for drought risk management in Africa, including the use of information in decision making processes, is a prerequisite and also capacity building actions are needed in order to promote a fruitful use of drought information. These must include not only training on the technological aspects of using such a tool, but also more basic activities such as raising drought risk awareness and demonstrating the drought risk management cycle. 
The tasks necessary to ensure a suitable use of drought information must be necessarily organized around scientific issues since before developing drought mitigation plans it is necessary to understand and consider the combinations of meteorological causes of drought, the analysis of historical climatic drought episodes. These may be used for determining the spatial and temporal variability of drought hazard and the vulnerability of water resources, vegetation systems and society to drought. But the technological component is also important, given the need to improve and develop Drought Information Systems for Africa, which include: seasonal / monthly drought hazard maps; drought vulnerability maps; real-time drought monitoring based on indicators; realtime drought early warning. It is also necessary to consider drought thresholds; vulnerability of water resources, rain-fed crops, natural ecosystems / pastures and forests; different socioeconomic sectors; seasonal drought forecasting and online training tools.

Therefore, the system must contain both geospatial information and derived products related to drought risk and vulnerability assessment, for the purpose of improving political decisions and management. A prerequisite is real-time information to assess the severity of droughts and the probable ongoing evolution in each part of the continent. Finally, it is necessary to understand the stakeholder and institutional arrangements, roles, responsibilities and capacity requirements so as to involve these stakeholders and institutions in drought initiatives, to develop appropriate products, to underpin the development of capacity as needed and to embed the products and knowledge developed within the drought mitigation plans.

Finally, it is necessary to make these data (and related metadata) accessible to the maximum extent possible. Hence interoperability appears also an important issue that can be achieved using standards like the one proposed by the Open Geospatial Consortium (OGC) and the International Organization for Standardization (ISO) and participating to initiatives like the Global Earth Observation System of Systems (GEOSS) (Giuliani et al., 2011). GEOSS is targeting nine so-called Societal Benefits Areas (SBAs) (Agriculture, Biodiversity, Climate, Disasters, Ecosystems, Energy, 
Health, Water, and Weather) in which drought monitoring and dissemination of relevant information in a timely manner is of major concern.

In summary, the main objective of any drought mitigation plan in Africa must be to contribute to enhance drought risk management in Africa through the development of fundamental drought information tools. The plan must make use of currently available information sources on meteorological and climatic data and remote sensing data to generate new information relevant for drought risk management. Thus at present, different tasks must be performed to solve different open questions that remain unsolved (Table 1). The available geospatial tools for the drought mitigation in Africa must be framed in a series of scientific and technical topics that are state-of-the-art. They are based on geospatial information, technologies and modeling approaches that can be summarized in the following issues: i) drought indicators; ii) drought hazard assessment; iii) drought vulnerability assessment; iv) drought monitoring and early warning; and v) drought forecasting. These will be summarized in the next five subsections.

\subsection{Drought indicators}

Given the difficulties in objectively identifying the onset and end of a drought, and in quantifying drought severity in terms of its duration, magnitude and spatial extent, much effort has been devoted to developing drought indicators for risk analysis and drought monitoring. We identify a drought by its effects at different levels, but there is not a single physical variable we can measure to quantify droughts. For this reason, drought indicators are the most essential element for drought analysis and monitoring since they enable identification and quantification of droughts. The establishment of a unique and universally accepted drought indicator does not exist, although a number of drought indicators have been proposed (Heim, 2002; Keyantash and Dracup, 2002; Mishra and Singh, 2010; Sivakumar et al., 2010). 
At present the two most widely used drought indicators are the Palmer Drought Severity Index (PDSI) (Palmer, 1965), based on a soil water balance equation and the Standardised Precipitation Index (SPI) (McKee et al., 1993), based on a precipitation frequency approach. The PDSI is based on the supply and demand concept of the water balance equation, and thus incorporates prior precipitation, moisture supply, runoff and evaporation demand at the surface level. The main shortcoming of the PDSI is its fixed temporal scale, which is a critical shortcoming in analyzing drought impacts, given the differences in characteristic drought resilience times of various natural and economic systems. In fact it has been widely demonstrated that the response to drought conditions of soil moisture level, river discharge, reservoir storage, vegetation activity, crop production, groundwater level and other environmental and economic variables occurs at very different time scales (e.g., Szalai et al., 2000; Ji and Peters, 2003; Vicente-Serrano and LópezMoreno, 2005; Vicente-Serrano et al., 2006; Patel et al., 2007; Vicente-Serrano, 2007; Khan et al., 2008). This explains the wide acceptance of the SPI, which can be calculated at different time scales (i.e., accumulated over given time spans) to monitor drought conditions affecting systems with different resilience times. The main criticism to the SPI is that its calculation is based solely on precipitation data, not considering other variables that determine drought conditions such as temperature, evapotranspiration, wind speed or the soil water holding capacity (Vicente-Serrano et al., 2011). Several studies, however, have shown that temperature markedly affects the severity of droughts through its control of the evapotranspiration demand (e.g., Abramopoulos et al., 1998; Breshears et al., 2005; Zhao and Running, 2010; Carnicer et al., 2011). Given the global temperature increase $\left(0.5\right.$ to $\left.2^{\circ} \mathrm{C}\right)$ during the last 150 years and that climate change models predict a marked increase during the 21 st century, it can be expected that temperature rise will have dramatic consequences for drought conditions (Naramsimhan and Srinivasan, 2005; Rebetez et al., 2006; Dubrovsky et al., 2008). To overcome this limitation, the Standardized Precipitation Evapotranspiration Index (SPEI) was recently developed (Vicente-Serrano et al., 2010b), which 
combines the sensitivity of PDSI to changes in evaporation demand caused by temperature with the multi-temporal nature of the SPI.

Although some studies applied drought indicators at the national and the regional scales in Africa (e.g., Ntale and Gan, 2003, Rouault and Richard, 2005), none of these drought indicators have been applied to the entire continent, nor has an inter-comparison of drought indicators has been made. A comparison of different drought indicators for the entire continent is a pre-requisite to assess drought hazard and vulnerability. Moreover, an assessment of the most appropriate indices and timescales in terms of the vulnerabilities of target systems would follow, as a necessary step to monitor droughts in the entire continent.

Moreover, with the exception of few examples (none in Africa), climate drought indicators have been scarcely tested in relation to their usefulness for monitoring drought vulnerability of hydrological, environmental and agricultural systems: soil moisture, river flows, reservoir storages and yields, real evapotranspiration, vegetation activity, leaf production, vegetation biomass and crop production. To test the capacity of different drought indicators for monitoring drought vulnerability to each system and in different regions is a first order requisite to develop a drought monitoring system for Africa. The use of the SPEI for the entire continent is highly promising since it allows establishing the impact of precipitation variability and warming processes on drought severity and to include not only precipitation forecasting but also temperature, with noticeable implications for climate change scenarios. Figures 2 and 3 show, respectively, the evolution of the SPEI in Nairobi (Kenya) between 1950 and 2010 and the 6-month SPEI from July to December 1984 when very extreme drought conditions affected the Sahel and East Africa. The evolution of the SPEI at Nairobi illustrate the changes in drought occurrence as a function of the time-scale. On the shorter time-scales ( 3 or 6 months), the dry and humid periods were short and had a highfrequency. At a time-scale of 12 or 24 months, droughts were less frequent, but they lasted longer. The use of the different time-scales allows one to reproduce the different times of response of 
hydrological systems, natural vegetation and cultivations to the availability of water (e.g., Ji and Peters, 2003; Vicente-Serrano, 2007; Lorenzo-Lacruz et al., 2010; Fiorillo et al., 2010; Vidal et al., 2010; Quiring and Ganesh, 2010) and to better identify drought impacts than drought indices that can only be calculated at a unique time-scale (Vicente-Serrano et al., 2011).

Therefore, the definition of accurate and suitable indicators for drought analysis and monitoring must be a basic objective of any drought mitigation plan in Africa. These indicators must be based on carefully processed climate information. The starting point of the creation of drought geospatial infrastructures must be the development of a database of several candidate drought indicators to overcome the current gaps, based on homogeneous climate information data for the entire continent. In Africa there are important problems in the collection and access to climatic information. Nevertheless, at present there are current low-resolution geospatial climatic products like the dataset of African climate data available at the Global Historical Climatology Network (GHCN) and other climatic sources (WMO telecommunication net, Climate Prediction Centre precipitation, etc. see http://climexp.knmi.nl/) that may be used to produce climate layers. In addition a global SPEI dataset is already available for the African continent at a spatial resolution of $0.5^{\circ}$ (Beguería et al., 2010), which can be used to assess drought risk and drought vulnerability in a variety of systems.

The development of distributed layers of drought indices, and their implementation in Geographic Information System (GIS) technologies, will be a definite advance in assessing the spatial and temporal variability of droughts in the African continent and to feed methodologies and systems to generate information directly related to management decisions and early warning systems.

\subsection{Drought hazard assessment products}

Central to the drought mitigation plan is a careful consideration of drought risk. We abide by a formal (and quantitative, e.g., Marin et al., 2004; Grünthal et al., 2006) definition of drought risk as a proportional combination of the likelihood of occurrence of a drought event (hazard) and the 
expected negative results that result from the occurrence of the drought (impact) (Blaikie et al., 1994). This results in the following fundamental equation of risk:

$$
\text { risk }=\text { hazard } \mathrm{x} \text { impact. }
$$

Drought hazard is expressed in terms of probability of a drought event occurring in a given place during a given period of time. Drought impact refers to the expected damage as a consequence of a drought episode, and is better expressed in terms of the costs generated on a set of vulnerable systems such as water resources, crops, etc. Hazard and impact curves must be computed for different degrees of drought severity. The development of drought impact curves will be covered in a following sub-section on vulnerability analysis.

Drought hazard assessment refers to determining the degree of hazard related to the occurrence of drought. More specifically, its goal is to quantify the magnitude / duration / frequency relationship of drought episodes in a particular region, expressed in terms of probability or its inverse, the expected return period. This is typically addressed by probabilistic analysis based on multivariate extreme value theory, based on historical climate records (Vicente-Serrano and Beguería, 2003; Lana et al., 2006; Shiau and Modarres, 2009; Saravi et al., 2009). Using data from a network of climate observatories or gridded climatologies it is possible to develop spatial models of drought hazard over target regions. Such models aid in assessing the spatial distribution of the degree of hazard and thus to identify the prone regions (e.g., Beguería et al., 2009).

Commonly drought risk assessment is based on a static approach assuming that the climate is stationary (i.e., that climatic variables do not have time trends nor cycles). However, it is well known that climate is characterized by a changing nature, exhibiting fluctuations, or even trends (e.g., global warming). Recently, non-stationary extreme value analysis methods have been developed which allow consider non-stationarity of climatic time series (Coles, 2001). These techniques have been applied to hydro-climatic hazards such as floods (Katz et al., 2002) and 
extreme precipitation (Beguería et al, 2011). No attempts exist to date to apply non-stationary techniques to the analysis of drought hazard.

In Africa there are very few examples of drought hazard assessment. Probably the unique example for the entire continent is the Global Risk Data Platform (Giuliani and Peduzzi, 2011) developed by the United Nations Environment Programme (UNEP) that, although useful, is based on a qualitative assessment during a period of 30 years, using a static (stationary) approach. Maps expressing quantitatively the probability of occurrence of drought in terms of drought severity characteristics such as duration, magnitude, and spatial extent obtained from drought indicators are necessary for the entire continent to constitute a complete hazard assessment.

Thus, the availability of spatial-temporal data sets of drought indicators that will allow the development of a historical catalogue of drought episodes that have affected any region of Africa must be the core of the fundamental data base for drought hazard assessment. Time series of drought characteristics at several time scales should be obtained and analyzed to define the probability of occurrence of drought episodes of given characteristics in any region of Africa. As a representative example, Figure 4 shows the exceedence probability curves for drought magnitude and duration at Nairobi, Kenya $\left(1.25^{\circ} \mathrm{S}, 36.7^{\circ} \mathrm{E}\right)$ on a common vertical numerical scale. The curves represent the maximum duration and magnitude of a drought episode in a period of $\mathrm{n}$ years. The drought episodes were defined following a threshold of the SPEI $=0$, considering a time-scale of 3 months. The SPEI was calculated using the CRU TS 3.1 dataset (Mitchell and Jones, 2005). Probabilities were obtained by fitting the drought magnitude and duration series to a Generalized Pareto distribution (see details of the method in Vicente-Serrano and Beguería, 2003 and in Vicente-Serrano et al., 2004). The availability of distributed drought indices for the different regions of Africa would allow the development of maps for the probability of drought magnitude and duration for the entire African continent. In addition, the use of newly developed techniques based on bivariate probability distribution models (Naradajah, 2009) would allow the determination 
of joint probabilities of drought duration, magnitude and spatial extent. This would go beyond the common stationary approach, applying techniques to determine if the drought risk is changing in time (or not), and where, as a consequence of climate change. This could produce detailed geospatial information available for taking more appropriate management decisions.

\subsection{Drought vulnerability assessment}

Drought vulnerability is an index of the inability of a society or an ecosystem to cope with drought, and is the sum of the impacts on the various elements of the system (e.g. water resources, crops, etc). Drought vulnerability is thus related to the degree of natural and social adaptation to drought, in terms of both resistance and resilience.

Drought vulnerability assessment is a complex task given the variety of the natural and social systems affected by drought, and a universally accepted method to quantitatively assess drought vulnerability is still missing. The UNEP recently developed a global evaluation of the human and economic exposure to drought by intersecting severity / hazard curves and the population and gross domestic product (http://preview.grid.unep.ch/). Nevertheless, the model did not include the evaluation of the hydrological, agricultural and ecological vulnerability to droughts, which are at the root of the social and economic consequences. The UNDP's Bureau for Crisis Prevention and Recovery (BCPR) developed a Disaster Risk Index (DRI) for droughts (Peduzzi et al., 2009). The index is based exclusively on the annual number of people dead between 1980 and 2000, and it is viewed as a function of physical exposure and vulnerability. However, the BCPR acknowledges that the drought DRI may not necessarily represent actual drought vulnerability given the uncertainties associated with the rough assumption made by directly associating the mortality rate with drought. A similar problem can be found on the Natural Disaster Hotspots project of the World Bank, which has assessed the global drought risks of two-disaster-related incomes: mortality and economic loss (World Bank, 2005). Nevertheless, the spatial detail of this assessment is too coarse 
and important systems vulnerable to drought are not taken into account. Although they are all interesting approaches to quantify human and economic vulnerability to drought at the society level they are highly indirect methods, since drought affects human societies mostly indirectly through its impact to the natural systems.

A critical deficiency in current vulnerability assessment practice is that the system's resilience (how the system recovers after a drought episode) is not accounted for. It is necessary to understand how the drought characteristics (duration, magnitude and intensity) affect the resilience times of the various systems (hydrological, ecological, environmental, agricultural, etc.), since this determines the persistence of the drought impact. Despite its importance, this element has not been taken into account in any drought vulnerability model.

Complete spatial coverage, good availability, accessibility, low cost and high temporal and spatial resolutions are strong advantages for using Earth Observation (EO) data for the analysis of drought vulnerability in Africa. This is because Africa is a continent where climatological and environmental data are often unavailable, inaccessible or expensive. Current EO satellites provide useful data relevant to assess the agricultural and environmental vulnerability to drought. The strong relationships between the spectral properties in the red and near-infrared parts of the electromagnetic spectrum and relevant vegetation properties allow assessment of land cover, vegetation productivity (Eklundh and Olsson, 2003, Hickler et al., 2005), dry matter production (Zhao et al., 2005, Sjöström et al., 2009), leaf area index (Fensholt et al., 2004), and soil moisture (Sinclair and Pegram, 2010) by means of satellite imagery. Recent work (Sjöström et al., 2009) reported strong linear relationships between the gross primary production (GPP) and spectral information at moderate spatial and high temporal resolutions. There are several studies that have analyzed the capability of EO data to determine the status of cultivation and natural vegetation in Africa (Diallo et al., 1991; Tucker et al., 1983 and 1991). In addition, numerous studies have analyzed the impacts of drought on vegetation activity and growth using remote sensing images 
(Milich and Weiss, 1997; Nicholson et al., 1998; Anyamba and Tucker, 2005; Heumann et al., 2007). These analyses are in the root of the current possibilities of assessing real-time impacts of droughts on vegetation coverage using EO data (e.g., Kogan, 1997).

The use of EO data and their derivatives together with solid analytical tools for time series analysis (Jönsson and Eklundh, 2002, 2004) yields promising possibilities for deriving descriptors of the seasonal vegetation development that are relevant for drought impact and vulnerability analysis. These include the beginning and end of the growing season, its length, strength, and timing. Studying the evolution of these measures through time allows for the detection of changes in the environmental conditions to determine both the start of the negative effects of a drought and the recovery after its end (Eklundh and Olsson, 2003), as well as long-term changes in the vegetation phenology and composition (Heumann et al., 2007). Combined analysis of time-series EO data with drought indicators will enable hypotheses to be tested regarding interactions and feedbacks between the vegetation and the climate system (Hickler et al., 2005; Vicente-Serrano, 2007; Seaquist et al., 2009; Jain et al., 2009), allowing the development of drought impact curves for cropland and natural vegetation areas. As a representative example of the assessment of drought vulnerability using EO data and drought indices, Figure 5 shows the correlation between the SPEI and the boreal fall NDVI (September-November) obtained from the GIMMS (Global Inventory Modeling and Mapping Studies) dataset obtained from NOAA-AVHRR satellites between 1982 and 2006 for the entire African continent. Although phenology annual patterns are very complex in the different African biomes, boreal fall season has been selected for the example as a consequence of the peak vegetation activity in the pastures of the Sahel and east Africa, which ate highly vulnerable to the climate variability. Since we cannot know in advance the most suitable drought time-scale to monitor drought vegetation conditions, since the times of response of the different vegetation types to the shortage in water availability can be very different, the map represents the local maximum correlation obtained for SPEI time-scales between 1 and 48 months. Areas with high correlations 
indicate that vegetation activity and growth is highly driven by climatic drought conditions. High values are found in most of the Sahel, East Africa and South Africa. This indicates that the vegetation and related human activities of these areas are highly vulnerable to drought.

At present, the longest record of processed EO data for land studies is the National Oceanic and Atmospheric Administration/ Advanced Very High Resolution Radiometer (NOAA/AVHRR) data that dates back to 1982 (8 $\times 8 \mathrm{~km}$ spatial resolution), whereas the MODerate-resolution Imaging Spectroradiometer (MODIS) database dates back to 2000 (250 x $250 \mathrm{~m}$ resolution). The European Spatial Agency (ESA) ENVISAT mission also generates spectral data at medium resolution (Medium Resolution Imaging Spectrometer Instrument -MERIS-; 350 m resolution), dating back to 2002. For continuing observations forward in time, ESA will be launching the Sentinel-3 satellite series which will carry spectrometers for medium and coarse resolution monitoring (300 - $1000 \mathrm{~m}$ spatial). This system of satellites is part of the ESA operational service for ocean and land monitoring, and the satellite mission is planned to be operational by 2013. Another very useful instrument will be the National Polar-orbiting Operational Environmental Satellite System (NPOESS) with circa 400 m resolution, planned for 2013-2026. Both these systems are planned for operational services, meaning that data delivery will be guaranteed for many years to come, which can improve the vulnerability assessment that can be done with lower spatial resolution platforms. In addition, various high-spatial resolution satellites have collected spectral information during the last 30 years (e.g., LANDSAT since 1972) allowing retrospective analysis of drought impacts on soil moisture, natural vegetation, land cover, land use and crops for past drought events. These data, with high spatial, but low temporal resolution, are useful for local calibration studies relating ground observations via high spatial resolution data to high temporal resolution EO data. Additionally, ecosystem resilience, i.e. the spatial and temporal pattern of vegetation recovery after a drought, can be studied using these historical EO archives (Prince et al, 2009). All EO data 
mentioned above can be analyzed in concert with other types of spatial data regarding population density, land cover and land use, factors that all can modify drought resistance and resilience.

Together with the assessment of the vulnerability to drought of natural vegetation and cultivation, another key sector is that related to the water resources, closely related to the availability and quality of the water. In this case, an accurate assessment of the drought impact on the water resources must be based on empirical studies relating time series of drought indicators with hydrological data records such as river discharge. Thus, from the river discharge information hydrological drought indicators can be derived to assess in real-time the severity ofa hydrological drought. An example is showed in Figure 6, where the evolution of hydrological drought indices (the Standardized Streamflow Index, SSI) (Vicente-Serrano et al., 2011b) for the Congo and Orange rivers are shown between 1945 and 2005. The streamflow series used to obtain the SSI were obtained from Dai et al. (2009). The series indicate that strong drought episodes affected the Congo basin in the decades of 1960 and 1970, whereas in the last decades the magnitude of the episodes has been much lower. On the contrary, in the Orange river the main drought episodes have been recorded since 1980. Relating the SSI with climatic drought indices like the SPEI would allow assessing how vulnerable the river systems are to the occurrence of climatic droughts and to determine the time-scales and periods of the year in which the vulnerability to the availability of water is most critical. Figure 7 shows the correlation between the SSI and the basin integrated SPEI at time-scales between 1 and 48 months in the Congo and Orange basins. It shows that hydrological droughts in the Congo basin are closely related to climatic droughts computed at time-scales between 3 and 10 months, depending also on the month of the year. For the Orange river we found more important seasonal differences, showing that between August and November there is no climatic influence to explain variability of streamflows in the basin.

If river flow data are available for the entire continent it is possible to develop maps of hydrological vulnerability to the occurrence of climatic droughts. Nevertheless, given the unavailability of 
hydrological data in some African countries, the outputs from the application of physically based climate-runoff models are an alternative. New methodologies and modeling approaches allow the simulation of different hydrological parameters with a high degree of accuracy and to distribute hydrological information throughout the territory. Hydrological models can estimate spatially distributed hydrological information that can be related to drought indicators to assess drought impact to the hydrological system (Beven, 1989). For example there are available streamflow simulations using the Soil and Water Assessment Tool (SWAT, Arnold et al., 1990) for the whole of Africa performed by the Swiss Federal Institute of Technology (Schuol et al., 2008). SWAT is a widely used conceptual model that allows a number of different processes to be simulated at the same time. The model simulates the major hydrologic components and their interactions as simply and yet as realistically as possible, and includes different variables of interest: soil moisture, river discharge and groundwater level. Moreover, the model is computationally efficient to operate in large basins in a reasonable computing time and is capable of simulating long time periods for assessing the effects of droughts of different severity. These simulations can be used for assessing hydrological vulnerability to climatic droughts in areas in which no gauging stations are available. Finally, it is also necessary to draw attention to human vulnerability, which results from physical, social, economic and environmental factors that determine the likelihood and scale of damage from the impact of a given hazard. Human vulnerability refers to the different variables that make people more or less able to absorb the impact and to recover from a hazard event. It includes anthropogenic variables (social, economic, demographic, etc.) that may increase the severity, frequency, extension and unpredictability of a hazard. Human vulnerability must be integrated with environmental vulnerability in the drought mitigation plans to make a complete and reliable estimation of droughtrelated risks.

Based on these data and by means of statistical analysis, the drought mitigation plans can calculate vulnerability curves for each region, which will relate drought severity to its expected impact on the 
various systems analyzed, in terms of both resistance and resilience. Moreover, since drought vulnerability may have changed in time due to changes in the frequency of droughts or changes in human and environmental resistance and resilience to drought, a temporal assessment of drought vulnerability must be an essential part of the drought plans.

As part of the objectives in the vulnerability analysis, and as a fundamental issue for developing a drought early warning system, the best drought indicators and time-scales must be determined that allow a better estimation of drought impacts on the different systems. Moreover, the approach must not only consider the impact of drought in terms of the resistance of the systems analyzed, but also in terms of their resilience. Based also on statistical time series analysis, the characteristic recovery times after a drought must be computed, and incorporated as a key factor of drought vulnerability when the geospatial information on drought vulnerability is generated.

\subsection{Drought monitoring and early warning}

The National Drought Mitigation Centre (NDMC) of the US has developed a widely accepted methodology for drought planning and preparedness (Wilhite, 1996). In summary, a drought plan must include a resources inventory, identification of the groups/communities at risk, integration of the stakeholders, diffusion of the preparedness plans and a periodic evaluation and revision of the plan. A critical component in the drought planning guidelines is the provision of timely and reliable climatic information which is in the base of management decisions (Wilhite, 2002; Wilhite et al., 2007; Iglesias et al., 2007). Drought monitoring is therefore crucial for the implementation of drought plans. The use of synthesized drought indicators informing one about the spatial extent and severity of drought conditions is a convenient way to express the level of risk in a way which is easily understood by end-users. A good drought indicator must consider different drought types and a variety of potential impacts, must be publicly accessible and provide up-to-date information (Svoboda et al., 2004). The most efficient approach to ensure free accessibility is by means of 
information technology, including the Internet and possibly other communication technologies. It is possible to implement such a system, integrating several sources of climate information, in an automated web server operating in real-time.

There are several examples of drought monitoring systems in developed countries. Several states in the US have their own drought monitoring system based on drought indicators, or including some other climatic/hydrological parameters (e.g., precipitation, temperature, evapotranspiration, streamflow, reservoir levels, etc.). At the national level the US Drought Monitor provides synthesized information about the severity of the drought conditions based on a composite drought indicator and distinguishing between two types of impacts (agricultural and hydrological) (Svoboda et al., 2002).

There are other examples of drought monitoring systems in Australia and South-eastern Europe (by the DMCSEE, Drought Management Centre for South-eastern Europe). In Europe the main initiative is currently being developed by the Institute of Environment and Sustainability of the Joint Research Centre (JRC) of the EC by means of the development of the JRC's Action DESERT. The JRC is currently developing a European Drought Observatory (EDO) for drought forecasting, assessment and monitoring with a system that includes real time monitoring of precipitation, soil moisture and satellite products.

Some initiatives for drought monitoring exist also in Africa. The experimental African Drought Monitor is operated for the entire continent by the Land Surface Hydrology Group at Princeton University with support from the UNESCO International Hydrology Program. The system provides near real-time monitoring of land surface hydrological conditions based on hydrological modeling. Available outputs include water budget components (precipitation, evapotranspiration, runoff, snow and soil moisture) but it does not provide synthetic information in terms of drought indicators. Within these kinds of continental approaches we must include the Global Drought Monitor, developed by the Department of Space and Climate physics of the University College London, 
which provides an 'overall drought picture' of the whole earth at a $\sim 100 \mathrm{~km}$ spatial scale. Nevertheless, the Global Drought Monitor is not designed to depict local conditions or to be the basis of a warning system due to its coarse spatial scale and being only based on the SPI and the PDSI indicators.

Probably the best drought monitoring system in Africa is the Africa Data Dissemination Service (ADDS) maintained by the US Geological Survey (USGS), including real time SPI, satellite information, rainfall estimates and soil moisture models (http://earlywarning.usgs.gov/adds/index.php). The system is an efficient real time tool (10 day resolution) including relevant drought-related parameters for the entire continent. Nevertheless, the drought indicators used in the ADDS can be improved, for example by including other drought indices sensitive to the global warming influence on drought conditions. Moreover, the satellite vegetation index-indicators included in the ADDS could be expressed as anomalies relative to the normal values as a means of measuring the severity of drought.

But the major shortcoming of current monitoring systems is that they have not been empirically tested in terms of the time scales and impacts, and this task is fundamental to guarantee their usefulness to monitor drought conditions in the different environmental, hydrological and socioeconomic systems. Finally, all national or regional initiatives to develop a drought monitoring system in Africa, such as the Drought Monitoring Centre of the Southern Africa Development Community or the Drought Monitoring Centre for the Greater Horn of Africa, are at present not operative in real time. Nevertheless, the technologies available and the cases indicated above are examples of the current capacity to develop a system that provides information on the drought conditions, types and derived impacts, based on the previous assessment of vulnerabilities and the availability of indicators and time-scales to determine the drought impacts across a variety of hydrological systems, ecological regions and social communities. 
The above examples demonstrate the possibilities of implementing a monitoring system based on real-time climatic data and historical knowledge of what are the 'normal' conditions for a given region and time of the year. Early warning can be based on drought monitoring and a thorough knowledge of the impacts of drought on different systems, by implementing a drought impact predictive model. In addition, the information provided by EO data can be used to develop real-time drought impact indicators for natural ecosystems and agriculture based on changes in the spectral signal during the growing season related to changes in the absorption of photosynthetically active radiation by the vegetation. Vegetation stress can be detected by comparing the current year's vegetation index trajectory with a normal curve of seasonal variation. Crops are often more vulnerable during the early stage of the cropping cycle (planting/sowing and initial root development) when we assume a relatively higher vulnerability/resilience for a given deviation from the normal curse as compared to natural vegetation. This way, drought impact on the natural vegetation and on crops would not need to be estimated from pre-defined impact curves, but could be directly monitored from near real-time EO data. Therefore, whereas climate data brings real-time information about the primary factors regulating climatological drought, remote sensing data can, due to its higher spatial resolution, provide better detail concerning the land cover types affected, and the effects of the climatic drought on the agricultural and natural vegetation. Previous approaches to drought monitoring have generally considered data from the NOAA-AVHRR data system. Today's and tomorrow's ESA environmental satellites (e.g. Envisat and Sentinel-3) will be better equipped to perform this monitoring since these data are better suited for land monitoring from radiometric, spectral, and geometric standpoints.

Therefore, it is necessary to bring together the outputs and advances in the issues indicated above to develop an operative real-time drought monitoring and early warning system for Africa, implemented as part of a more complete Drought Information System. The system must be optimized in terms of the best drought indicators to monitor drought in relation to the drought 
vulnerability of various target systems, like the SPEI allows to assess, and it must include a forecast of the likely evolution of the drought conditions over the following months. The system must be based on a map server, and the information be automatically generated based on available data sources (climatology and satellite imagery), and be updated with a high temporal frequency. Thus, drought mitigation plans must use near real-time remote sensing data for enhancing the functionality of the drought monitoring and early warning systems in the entire continent allowing a full integration of the information provided by geospatial climate drought indicators and satellite data.

\subsection{Drought forecasting}

At present, drought forecasting can be fully embedded in the seasonal forecasting provided by Global Climate Models (GCMs). Much effort has been made to reduce the uncertainties of longterm climatic forecasting given its evident social and economic applicability (Thomson et al., 2006). The project DEMETER was a landmark in relation to this issue, since in the frame of this project a multi-model ensemble system for seasonal to interannual forecasting in Europe was developed that incorporated a representation of the model uncertainty (Palmer et al., 2004). The European Centre for Medium-Range Weather Forecasts (ECMWF), an independent organization supported by 31 states across Europe, has extended the model's predictions to other regions of the world. Now, the European centre maintains a seasonal forecast up to four months lead in time for the entire Africa. The prediction is based on an ensemble of GCMs, which provides a reasonable skill (Palmer et al., 2005). Thus, an ensemble mean and associated probabilities are publicly available for temperature, precipitation and other climatic variables which make computing drought indicators possible (http://www.ecmwf.int/products/forecasts/d/charts/seasonal/forecast/). Other meteorological agencies, like the National Center for Environmental Prediction (NCEP) in the US also provide long-term meteorological forecasting in Africa (Saha et al., 2006). 
Although useful, the uncertainty of model-based predictions is very high. Hence, for operative purposes it is advisable to combine this approach with other, empirically based, predictions. Empirically based methods for drought forecasting have been developed based on the current values of drought indicators, the historical frequency of rains and some external factors as predictors. Sea surface temperatures have shown a reasonable skill in different regions of the world as a potential predictor of precipitation anomalies some months in advance (Mutai et al., 1998; Rodwell et al., 1999; Camberlin et al., 2001; Philippon et al., 2002). In the same way, data on teleconnection patterns such as the North Atlantic Oscillation (NAO), the Arctic Oscillation (AO), the El Niño Southern Oscillation (ENSO), the Indian Ocean Dipole, convective activity indices, solar radiation activity and other climate drivers could help improving the predictive capability of empirically based methods in Africa (Hoerling et al., 1997; Rowell, 2001; Saji et al., 1999; Saji and Yamagata, 2003; Nicholson and Webster, 2007). For example, it is known that a heating of the subtropical region of the Atlantic Tripole in summer is related to a weakening of the Azores anticyclone, that is, to a negative phase of NAO index in the next winter and vice versa. This configuration produces significant anomalies in winter precipitation in Northern Africa (Rodriguez-Fonseca and Castro, 2002).

The known relationship between ENSO and the Asian monsoon (Webster and Yang, 1992) and between the Madden-Julian Oscillation and the African Monsoon (Pohl et al., 2009) could supply predictability skill to the rainfall anomalies and droughts over central and Western Africa. Previous studies also show that Eastern Africa is in phase with warm ENSO episodes, whereas southern Africa is negatively correlated with these events (Nicholson and Kim, 1997). ENSO is the most dominant perturbation responsible for interannual climate variability over eastern and southern Africa (Nicholson and Entekhabi, 1986) and the Sahel (Janicot et al., 1996; Janicot et al., 2001). Figure 8 shows, as a representative example, the average SPEI in Africa corresponding to the month of August of El Niño years (see more details in Vicente-Serrano et al., 2011c). It is clear that in 
most of the continent negative 6-month SPEI values are recorded, indicative of severe dry conditions in the South, Southeast and the Sahel during El Niño years. Forecasts of the ENSO phases could then improve drought prediction in Africa. Nevertheless, we must be aware that although these forecast are routinely provided and distributed today, the limits of El Niño predictability are still the subject of debate (Philander and Fedorov, 2003; Palmer et al., 2004). However, major efforts and advances are being made in this field and the prediction of ENSO events has increased with the refinement of numerical models (Chen et al., 2004; Tippet and Barnston, 2008; Jin et al., 2008), which may allow one to predict spatial patterns of impacts with certainty to allow the development of adaptive response.

Compared to drought monitoring, drought forecasting is still in a precarious state (Murphy et al., 2001). As of now, the only system offering drought forecasts is the NOAA's Cimate Prediction Center (CPC), in which an outlook informing on the foreseen evolution of the drought conditions is provided at a seasonal time scale (http://www.cpc.ncep.noaa.gov/products/expert_assessment/seasonal_drought.html). The prediction is based on a mixture of sources such as the Constructed Analogue on Soil moisture, the Climate Forecast System seasonal precipitation forecasts, the El Niño precipitation and temperature composites for November-January, normal climatology, and the current drought conditions (Schubert et al., 2007).

Therefore, the best option for drought forecasting in Africa must be based on a combination of the two approaches explained above: i) seasonal precipitation and temperature predictions for Africa based on Global Climate Models (GCMs) by the ECMWF and/or NCEP, from which expected drought indices values can be calculated; and ii) empirical prediction of drought indices based on atmospheric and oceanic precursors, adapted to the meteorology of each African region. The development of a statistical methodology to integrate both approaches and to reduce the uncertainties associated to seasonal forecasts have not been used in Africa but they have obtained 
promising results in other regions of the world (e.g., Frias et al., 2010). Given the large uncertainties involved in the seasonal climate forecasting it is not expected to provide an accurate determination of the future drought conditions, but an approximation on whether the drought can persist or intensify or if some improvement is expected like that is provided for the US by the CPC. Including the whole African continent in a forecasting system is a challenge given the atmospheric and climatic diversity of the region and the fact that integration of a process-driven (GCM) prediction and an empirical prediction has never been applied in the frame of drought forecasting. However, efforts are necessary to provide real-time predictions of the likely evolution of the current drought conditions over Africa to be implemented as part of a more complete Drought Information System that integrates the other static and dynamic geospatial information. The system should provide forecasts in terms of the probability associated to both alleviation and worsening of the current drought conditions at several time scales (from one week to a few months), as a way to express the uncertainty involved in the prediction.

\section{Capacity building}

Capacity building on drought management planning and specifically on the use of geospatial drought information products is of paramount importance for achieving the desired level of impact on the end-users and, in general, to improve the management of drought hazard in Africa. On the contrary, without a strong participation of the African communities at different decision levels the access to the climatic information will not improve the lives of the local communities (Tarhule and Lamb, 2003).

Capacity building needs to be recognized as being very multi-dimensional in nature. A number of authors (e.g., Godfrey et al., 2002; Calain, 2007) have discussed the challenges faced by donordriven projects or international support programs. Without sufficient dialogue and effort to effectively embed such support initiatives these well intended undertakings can prove fruitless or 
even damaging. The recipient countries really need to understand the benefits and take ownership, but the system also needs to meet the in-country requirements and be appropriate for the institutional framework and culture. The initiatives conducted to develop drought mitigation plans must understand the needs and requirements of the various countries and organizations so that the tools developed are indeed appropriate. Furthermore, throughout the development of drought information systems ongoing dialogue and discussion must be critical and further serve to embed the approach and the various tools and datasets. Whilst the most obvious aspect of capacity building will be actual training of staff on how to access and use the available static and dynamic geospatial information, it is equally important that some capacity building is included at executive management and even political levels so decision makers will be aware of the tools and information that are available.

Three key principles underpin the drive to build capacity. Firstly, the use of local coordination to support and drive the processes such that these are correctly framed for the local context, but also to ensure that communication is in appropriate languages and effectively targeted. Secondly, that already established structures and forums should be utilized wherever possible and that new focus groups are established only where needed due to an institutional vacuum. Thirdly, the capacity building program needs to tie in, or link in, with other capacity building programs that are relevant. With this in mind, the involvement of African researchers and managers in capacity building activities is essential. Training courses and workshops for institutional resource managers focused on urban and irrigation water management may provide efficient forums to discuss and understand the potential uses and limitations of Drought Preparedness Plans, geospatial data and drought information systems in their planning and decision-making activities.

Organizations such as the FAO Regional Office for the Near East (FAO-RNE), the International Centre for Agricultural Research in the Dry Areas (ICARDA) and the International Centre for Advanced Mediterranean Agronomic Studies (CIHEAM) have been historically involved in 
promoting capacity building through training courses, workshops and seminars on drought risk management. Nevertheless, capacity building must go beyond these initiatives and focus on different levels, at the same time improving the use of current technologies and information on drought conditions and predictions that provide drought monitoring and early warning systems for better and early decision making: i) supra-national: focused on organizations and NGOs that operate in Africa; ii) national governments; and iii) local communities.

Finally, capacity sharing must be an important consideration. Geospatial data is an expensive resource, and for this reason it is of high importance to improve its accessibility and availability and promote its reuse. Many decisions that organizations need to make depend on good quality and consistent data, which needs to be readily available and accessible. Therefore, the development of institutional linkages to share capacity would have clear longer term benefits for institutions and the efficacy of the plans.

Therefore, any drought mitigation plan based on the drought monitoring and different levels of geospatial information must develop a two-way communication tool for information exchange with the purpose of adapting the capacities of the drought information system to the needs and technical capacity of the users. This communication tool may also involve an online open forum, as well as stakeholder involvement techniques such as focus-groups, meetings and interviews. Capacity building for the more technically inclined must also be addressed by online open tutorials covering the use of drought information technology as well as broader topics on drought risk management. However, it must be noted that stakeholders must be enabled via the ongoing engagement processes.

\section{Conclusions}

Mitigation of drought hazard in Africa must be considered following a holistic perspective: from the collection of new information relevant for drought knowledge and management in Africa, the 
development, improvement and testing of new techniques for a better understanding and monitoring of droughts, to the developing of real-time information and forecasting systems to assist the preparedness, management and mitigation of drought risk in the entire continent. Other studies have already showed the potential use of geospatial information for warning issues. Vörösmarty et al. (2005) showed the possibilities of using earth datasets to determine the availability and temporal variability of water resources in Africa, indicating that chronic overuse and water stress in high for $25 \%$ of the population. In this study we have shown that dynamic information, including time-series of drought indices, can be used both for water and land management and for real time drought monitoring that allows promote early warning under emergency water stress related to severe droughts.

There are different key issues determinant for drought mitigation in Africa, which the use of geospatial datasets and real time information could help to solve:

- The development of a comprehensive data base of climatic drought indices for Africa could allow the completion of a historical drought data base of Africa which would permit the understanding of the behavior of this phenomenon over the entire continent and what kind of changes have been recorded in the last decades.

- The combination of state-of-the art methods of drought hazard analysis (spatial-temporal, nonstationary, multivariate extreme events analysis) would provide maps of the probability of occurrence of droughts in terms of their duration, intensity and magnitude, in order to identify (and quantify) the most drought-prone regions and the presence (or not) of long-term time trends in the severity of droughts.

- The assessment of the drought vulnerability of several systems (water resources, natural vegetation and crops) to quantify the impact of drought in terms of both the system's resistance and resilience, and to produce drought impact curves to each system and region. 
- State-of-the art remote sensing techniques allow using near real-time EO data to directly monitor the impact of drought to natural vegetation and crops.

- The knowledge of the connections between drought and its atmospheric and oceanic meteorological precursors across Africa may improve drought forecasting by means of the integration of model based long term weather forecasts and empirically based predictions based on atmospheric and oceanic precursors with the purpose of producing long term drought condition predictions.

- The possible implementation of a drought monitoring, early warning and forecasting system for the entire Africa based on the methods and the geospatial datasets indicated above.

In addition, these issues must be linked with:

- Formal (institutional) and informal setups to cope with drought risk in Africa and to determine the best approaches for improving capacity building on drought risk management.

- The development of capacity building tools for improving drought risk perception, introducing the concepts and tools of drought management, and for training the potential end-users in the use of drought information tools available in the drought monitoring systems.

It is acknowledged that accurate information is at the base of improving decision making, not only for drought risk management but also for other environmental and economic reasons. The methods, relationships and tools indicated in this article, and a better understanding of drought vulnerability, must allow for better preparedness, management and mitigation of drought risk in the region, which could help solving current deficiencies in adaptation and to integrate local adaptation strategies within national and supranational policies (Twomlow et al., 2008; Stringer et al., 2009; Conway and Schipper, 2011).

Geospatial technologies are able to contribute a deep integral assessment and monitoring of drought hazard in the most vulnerable continent of the world. The primary goal of cooperation policies in Africa are poverty reduction, and drought mitigation plans using geospatial technologies clearly 
focus on this issue since large human communities in Africa are closely dependent on natural resources and subsistence agriculture for their livelihood. Drought regularly causes impoverishment and triggers health and humanitarian crises.

\section{Acknowledgements}

This work has been supported by the research projects CGL2006-11619/HID, CGL200801189/BTE, CGL2011-27574-CO2-02, CGL2011-27753-CO2-01 and CGL2011-27536 financed by the Spanish Commission of Science and Technology and FEDER, EUROGEOSS (FP7-ENV2008-1-226487), AfroMaison (Grant agreement no 266379) and ACQWA (Grant Agreement $\mathrm{n}^{\circ} 212250$ ) financed by the 7th Framework Programme of the European Commission, "La nieve en el Pirineo Aragonés y su respuesta a la variabilidad climática" and "Efecto de los escenarios de cambio climático sobre la hidrología superficial y la gestión de embalses del Pirineo Aragonés" financed by "Obra Social La Caixa" and the Aragón Government and Influencia del cambio climático en el turismo de nieve. CTTP01/10, Financed by the Comisión de Trabajo de los Pirineos. 


\section{References}

Antwi-Agyei, P., Fraser, E.D.G., Dougill, A.J., Stringer, L.C., \& Simelton, E. (2012). Mapping the vulnerability of crop production to drought in Ghana using rainfall, yield and socioeconomic data. Applied Geography, 32, 324-334.

Anyamba, A., \& Tucker, C.J. (2005). Analysis of Sahelian vegetation dynamics using NOAAAVHRR NDVI data from 1981-2003. Journal of Arid Environments, 63, 596-614

Arnold, J.G., Allen, P.M. \& Bernhardt, G. (1993). A comprehensive surface-groundwater flow model. Journal of Hydrology, 142, 47-69.

Bandyopadhyay, S., Kanji, S., \& Wang, L. (2012). The impact of rainfall and temperature variation on diarrheal prevalence in Sub-Saharan Africa. Applied Geography, 33, 63-72.

Barbier, B., Yacouba, H., Karambiri, H., Zorome, M., \& Some, M. (2009). Human Vulnerability to Climate Variability in the Sahel: Farmers' Adaptation Strategies in Northern Burkina Faso. Environmental Management, 43, 790-803

Batterbury, S., \& Warren, A. (2001). The African Sahel 25 years after the great drought: assessing progress and moving towards new agendas and approaches. Global Environmental Change, $11,1-8$.

Beguería, S., Vicente-Serrano, S.M., López-Moreno, J.I., \& García-Ruiz, J.M. (2009). Annual and seasonal mapping of peak intensity, magnitude and duration of extreme precipitation events across a climatic gradient, North-east Iberian Peninsula. International Journal of Climatology, 29, 1759-1779.

Beguería, S., Vicente-Serrano, S.M., \& Angulo, M. (2010). A multi-scalar global drought data set: the SPEIbase: A new gridded product for the analysis of drought variability and impacts. Bulletin of the American Meteorological Society, 91, 1351-1354.

Beguería, S., Angulo-Martínez, M., Vicente-Serrano, S.M., López-Moreno, J.I. \& Kenawy, A. (2011). Assessing temporal trends in extreme precipitation by non-stationary peaks-over- 
threshold analysis, NE Spain 1930-2006. International Journal of Climatology, 31, 21022114

Beven, K. (1989). Changing ideas in hydrology - The case of physically-based models. Journal of Hydrology, 105, 157-172.

Bhavnani, R., Vordzorgbe, S., Owor, M., \& Bousquet, F., (2008). Report on the status of disaster risk reduction in the sub-saharian Africa region. Commission of the African Union, United nations and the World Bank. http://www.unisdr.org/files/2229__RRRinSubSaharanAfricaRegion.pdf

Blaikie, P., Cannon, T., Davis, I., \& Wisner, B. (1994). At risk, natural hazards, people's vulnerability, and disasters. Routledge, London. 256 pp.

Breshears, D.D. et al. (2005). Regional vegetation die-off in response to global-change-type drought. Proceedings of the National Academy of Sciences of the United States of America, $102,15144-15148$.

Brown, C., Meeks, R., Hunu, K., \& Yu, W. (2011). Hydroclimate risk to economic growth in subSaharan Africa. Climatic Change, 106, 621-647.

Bruce, J.P. (1994). Natural disaster reduction and global change. Bulletin of the American Meteorological Society, 75, 1831-1835.

Burke, M., Miguel, E., Satyanath, S., Dykema, J.A., \& Lobell, D.B. (2009). Warming increases the risk of civil war in Africa. Proceedings of the National Academy of Sciences of the United States of America, 106, 20670-20674.

Burton, I., Kates, R.W., \& White, G.F. (1978). The environment as hazard. Oxford University Press. Nueva York, 240 pp.

Calain, P. (2007). From the field side of the binoculars: A different view on global public health surveillance. Health Policy and Planning, 22, 13-20. 
Camberlin, P., Janicot, S., \& Poccard, I. (2001). Seasonality and atmospheric dynamics of the teleconnection between African rainfall and tropical sea-surface temperature: Atlantic vs. ENSO. International Journal of Climatology, 21, 973-1005.

Carbone, G.J., Rhee, J., Mizzell, H.P., \& Boyles, R. (2008). Decision support: A regional-scale drought monitoring tool for the Carolinas. Bulletin of the American Meteorological Society, $89,20-28$.

Carnicer, J. et al. (2011). Widespread crown condition decline, food web disruption, and amplified tree mortality with increased climate change-type drought. Proceedings of the National Academy of Sciences of the United States of America, 108, 1474-1478.

Chen, D., Cane, M. A., Kaplan, A., Zebiak, S.E., \& Huang, D.J. (2004). Predictability of El Nino over the past 148 years, Nature, 428, 733- 736.

Coles, S. (2001). An introduction to statistical modeling of extreme values. Springer-Verlag: London.

Conway, D., \& Schipper, E.L.F. (2011). Adaptation to climate change in Africa: Challenges and opportunities identified from Ethiopia. Global Environmental Change, 21, 227-237.

CRDE (2011). The Centre for Research on the Epidemiology of Disasters. Disasters Database. http://www.cred.be/emdat/intro.htm. Universite Catholique de Louvain - Brussels Belgium.

Dai, A., Qian, T., Trenberth, K.E. \& Milliman, J.D. (2009). Changes in continental freshwater discharge from 1948-2004. Journal of Climate, 22, 2773-2791.

Dai, A. (2011). Drought under global warming: a review. Wiley Interdisciplinary Reviews: Climate Change, 2, 45-65.

Diallo, O., Diouf, A., Hanan, N.P., Ndiaye, A., \& Prévost, Y. (1991). AVHRR monitoring of savanna primary production in Senegal, West Africa: 1987-1988. International Journal of Remote Sensing, 12, 1259-1279. 
Dinar, A., \& Keck, A. (2000). Water supply variability and drought impact and mitigation in subSaharan Africa. In: Wilhite, D.A. (Ed.), Drought: A Global Assessment. Routledge, London. Dracup, J.A., Lee, K., \& Paulson, E.G. (1980). On the definition of droughts. Water Resources Research, 16, 297-302.

Dubrovsky, M., Svoboda, M.D., Trnka, M., Hayes, M.J., Wilhite, D.A., Zalud, Z., \& Hlavinka, P. (2008). Application of relative drought indices in assessing climate-change impacts on drought conditions in Czechia. Theoretical and Applied Climatology, 96, 155-171.

Eklundh L., Johansson, T., \& Solberg, S. (2009). Mapping insect defoliation in Scots pine with MODIS time-series data. Remote sensing of Environment, 113, 1566-1573.

Eklundh, L., \& Olsson. L. (2003). Vegetation index trends for the African Sahel 1982-1999, Geophysical Research Letters, 30, 1430.

Fiorillo, F., \& Guadagno, F.M. (2010). Karst spring discharges analysis in relation to drought periods, using the SPI. Water Resources Management, 24, 1867-1884.

Frías M.D., Herrera, S., Cofiño, A.S., \& Gutiérrez, J.M. (2010). Assessing the Skill of Precipitation and Temperature Seasonal Forecasts in Spain. Windows of Opportunity Related to ENSO Events. Journal of Climate, 23, 209-220.

Giuliani G., \& Peduzzi P. (2011). The PREVIEW Global Risk Data Platform: a geoportal to serve and share global data on risk to natural hazards. Natural Hazards and Earth System Sciences, 11, 53-66

Giuliani G., Ray N., Schwarzer S., De Bono A., Dao H., Peduzzi P., Beniston M., Van Woerden J., Witt R., \& Lehmann A. (2011). Sharing environmental data through GEOSS. International Journal of Applied Geospatial Research, 2, 1-17

Godfrey, M., Sophal, C., Kato, T., Vou Piseth, L., Dorina, P., Saravy, T., Savora, T., \& Sovannarith, S. (2002). Technical assistance and capacity development in an aid-dependent economy: The experience of Cambodia. World Development, 30, 355-373. 
Grünthal, G., Thieken, A.H., Schwarz, J., Radtke, K.S., Smolka, A., \& Merz, B. (2006). Comparative risk assessments for the city of Cologne - Storms, floods, earthquakes. Natural Hazards, 38, 21-44.

Havens, A.V. (1954). Drought and agriculture. Weatherwise, 7, 51-55.

Heim, R.R. (2002). A review of twentieth-century drought indices used in the United States. Bulletin of the American Meteorological Society, 83, 1149-1165.

Heumann, B.W., Seaquist, J.W., Eklundh, L., \& Jönsson, P. (2007). AVHRR Derived Phenological Change in the Sahel and Soudan, Africa, 1982 - 2005. Remote Sensing of Environment, 108, 385-392.

Hickler, T., Eklundh, L., Seaquist, J., Smith, B., Ardö, J., Olsson, L., Sykes, M., \& Sjöström, M. (2005). Precipitation controls Sahel greening trend. Geophysical Research Letters, 32, L21415.

Hoerling, M.P., Kumar, A., \& Zhong, M. (1997). El Niño, La Niña, and the nonlinearity of their teleconnections. Journal of Climate, 10, 1769-1786.

Holden, S., \& Shiferaw, B. (2004). Land degradation, drought and food security in a less-favoured area in the Ethiopian highlands: a bio-economic model with market imperfections. Agricultural Economics, 30, 31-49

Iglesias, A., Garrote, L., Flores, F., \& Moneo, M. (2007). Challenges to manage the risk of water scarcity and climate change in the Mediterranean. Water Resources Management, 21, 775788.

Jain, S.K., Keshri, R., Goswami, A., Sarkar, A., \& Chaudhry, A. (2009). Identification of droughtvulnerable areas using NOAA AVHRR data. International Journal of Remote Sensing, 30, 2653-2668.

Janicot, S., Moron, V., \& Fontaine, B. (1996). Sahel droughts and ENSO dynamics. Geophysical Research Letters, 23, 515-518 
Janicot, S., Trzaska, S., \& Poccard, I. (2001). Summer Sahel-ENSO teleconnection and decadal time scale SST variations. Climate Dynamics, 18, 303-320

Jankowska, M.M., Lopez-Carr, D., Funk, Dh., Husak, G.J., \& Chafe, A.A. (2012). Climate change and human health: Spatial modeling of water availability, malnutrition, and livelihoods in Mali, Africa. Applied Geography, 33, 4-15.

Ji, L., \& Peters, A.J. (2003). Assessing vegetation response to drought in the northern Great Plains using vegetation and drought indices. Remote Sensing of Environment, 87, 85-98.

Jin, E.K., Kinter III, J.L., Wang, B., et al. (2008). Current status of ENSO prediction skill in coupled ocean-atmosphere models. Climate Dynamics, 31, 647-664.

Jönsson, P., \& Eklundh, L. (2002). Seasonality extraction and noise removal by function fitting to time-series of satellite sensor data, IEEE Transactions of Geoscience and Remote sensing, $40,1824-1832$.

Jönsson, P., \& Eklundh, L. (2004). Timesat - a program for analyzing time-series of satellite sensor data, Computers and Geosciences, 30, 833 - 845.

Katz, R.W., Parlange, M.B., \& Naveau, P. (2002). Statistics of extremes in hydrology. Advances in Water Resources, 25, 1287-1304.

Keyantash, J., \& Dracup., J. (2002). The quantification of drought: an evaluation of drought indices. Bulletin of the American Meteorological Society, 83, 1167-1180.

Khan, S., Gabriel, H.F., \& Rana, T. (2008). Standard precipitation index to track drought and assess impact of rainfall on watertables in irrigation areas. Irrigation and Drainage Systems, 22, $159-177$.

Kogan, F.N. (1997). Global drought watch from space. Bulletin of the American Meteorological Society, 78, 621-636. 
Lana, X., Martínez, M.D., Burgueño, A., Serra, C., Martín-Vide, J., \& Gómez, L. (2006). Distributions of long dry spells in the Iberian Peninsula, years 1951-1990. International Journal of Climatology, 26, 1999-2021.

Lorenzo-Lacruz, J., Vicente-Serrano, S.M., López-Moreno, J.I., Beguería, S., García-Ruiz, J.M., \& Cuadrat, J.M. (2010). The impact of droughts and water management on various hydrological systems in the headwaters of the Tagus River (central Spain). Journal of Hydrology, 386, 13-26..

Marin, S., Avouac, J.-P., Nicolas, M., \& Schlupp, A. (2004). A probabilistic approach to seismic hazard in metropolitan France. Bulletin of the Seismological Society of America, 94, 21372163.

McKee, T.B.N., Doesken, J., \& Kleist, J. (1993). The relationship of drought frequency and duration to time scales. Eight Conf. On Applied Climatology. Anaheim, CA, Amer. Meteor. Soc. 179-184.

Milich, L., \& Weiss, E. (1997). Characterization of the Sahel: implications of correctly calculating interannual coefficient of variation (CoVs) from GAC NDVI values. International Journal of Remote Sensing, 18, 3749-3759.

Mishra, A.K., \& Singh, V.P. (2010). A review of drought concepts. Journal of Hydrology, 391, 202-216.

Mitchell, T.D., \& Jones, P.D. (2005). An improved method of constructing a database of monthly climate observations and associated high-resolution grids. International Journal of Climatology, 25, 693-712.

Murphy, S.J., et al. (2001). Seasonal Forecasting for Climate Hazards: Prospects and Responses. Natural Hazards, 23, 171-196. 
Mutai, C.C., Ward, M.N., \& Colman, A.W. (1998). Towards the prediction of the East Africa short rains based on sea-surface temperature-atmosphere coupling. International Journal of Climatology, 18, 975-997.

Nadarajah, S. (2009). A bivariate Pareto model for drought. Stochastic Environmental Research and Risk Assessment, 23, 811-822.

Narasimhan, B., \& Srinivasan, R. (2005). Development and evaluation of Soil Moisture Deficit Index (SMDI) and Evapotranspiration Deficit Index (ETDI) for agricultural drought monitoring. Agricultural and Forest Meteorology, 133, 69-88.

Nicholson, S.E., \& Kim, J. (1997). The relationship of the El Niño-Southern Oscillation to African rainfall. International Journal of Climatology, 17, 117-135.

Nicholson, S.E., Tucker, C.J., \& Ba, M.B. (1998). Desertification, drought and surface vegetation: an example from the west African Sahel. Bulletin of the American Meteorological Society, $79,815-829$.

Nicholson, S.E., \& Webster, P.J. (2007). A physical basis for the interannual variability of rainfall in the Sahel. Quarterly Journal of the Royal Meteorological Society, 133, 2065-2084.

Ntale, H.K., \& Gan, T.Y. (2003). Drought indices and their application to East Africa. International Journal of Climatology, 23, 1335-1357.

Obasi, G.O.P. (1994). WMO`s role in the international decade for natural disaster reduction. Bulletin of the American Meteorological Society, 75, 1655-1661.

Palmer, W.C. (1965). Meteorological droughts. U.S. Department of Commerce Weather Bureau Research Paper 45, 58 pp.

Palmer, T.N. et al., (2004). Development of a European multimodel ensemble system for seasonalto-interannual prediction (DEMETER). Bulletin of the American Meteorological Society, 85, 853-872. 
Palmer, T.N., Shutts, G.J., Hagedorn, R., Doblas-Reyes, F.J., Jung, T. \& Leutbecher, M. (2005). Representing model uncertainty in weather and climate prediction. Annual Review of Earth and Planetary Sciences, 33, 163-193

Patel, N.R., Chopra, P., \& Dadhwal, V.K. (2007). Analyzing spatial patterns of meteorological drought using standardized precipitation index. Meteorological Applications, 14, 329-336.

Peduzzi P., Dao H., Herold C. \& Mouton F. (2009). Assessing global exposure and vulnerability towards natural hazards: the Disaster Risk Index. Natural Hazard and Earth System Science, 9, 1149-1159

Philander, S.G., \& Fedorov, A. (2003). Is El Niño sporadic or cyclic?. Annual Review of Earth and Planetary Sciences, 31, 579-594.

Philippon, N., Camberlin, P., \& Fauchereau, N. (2002). Empirical predictability study of OctoberDecember East African rainfall. Quarterly Journal of the Royal Meteorological Society, $128,2239-2256$.

Pohl, B., Janicot, S., Fontaine, B., \& Marteau, R., (2009). Implication of the Madden-Julian oscillation in the 40-day variability of the West African monsoon. Journal of Climate, 22, $3769-3785$.

Prince, S.D., Becker-Reshef, I., \& Rishmawi, K. (2009). Detection and mapping of long-term land degradation using local net production scaling: Application to Zimbabwe. Remote Sensing of Environment, 113, 1046-1057.

Quiring, S.M., \& Ganesh, S. (2010). Evaluating the utility of the Vegetation Condition Index (VCI) for monitoring meteorological drought in Texas. Agricultural and Forest Meteorology, 150, 330-339.

Rebetez, M. et al. (2006). Heat and drought 2003 in Europe: A climate synthesis. Annals of Forest Science, 63, 569-577. 
Rodima-Taylor, D. (2012). Social innovation and climate adaptation: Local collective action in diversifying Tanzania. Applied Geography, 33, 128-134.

Redmond, K.T. (2002). The depiction of drought. Bulletin of the American Meteorological Society, $83,1143-1147$.

Rodriguez-Fonseca, B., \& de Castro, M. (2002). On the connection between winter anomalous precipitation in the Iberian Peninsula and North West Africa and the summer subtropical Atlantic sea surface temperature. Geophysical Research Letters, 29, 1863, doi:10.1029/2001GL014421.

Rowell, D.P. (2001). Teleconnections between the tropical Pacific and the Sahel. Quarterly Journal of the Royal Meteorological Society, 127, 1683-1706.

Rouault, M., \& Richard, Y. (2005). Intensity and spatial extent of droughts in southern Africa. Geophysical Research Letters, 32, L15702, doi:10.1029/2005GL022436.

Saha, S., Nadiga, S., Thiaw, C., Wang, J., et al. (2006). The NCEP Climate Forecast System. Journal of Climate, 19, 3483-3517

Saji, N.H., Goswaml, B.N., Vinayachandran, P.N., \& Yamagata, T. (1999). A dipole mode in the tropical Indian ocean. Nature, 401, 360-363.

Saji, N.H., \& Yamagata, T. (2003). Possible impacts of Indian Ocean Dipole mode events on global climate. Climate Research, 25, 151-169.

Saravi, M.M., Safdari, A.A., \& Malekian, A. (2009). Intensity-duration-frequency and spatial analysis of droughts using the standardized precipitation index. Hydrology and Earth System Sciences Discussions, 6, 1347-1383.

Scheffran, J., Marmer, E., \& Sow, P. (2012). Migration as a contribution to resilience and innovation in climate adaptation: Social networks and co-development in Northwest Africa Original Research Article. Applied Geography, 33, 119-127. 
Schubert, S., Koster, R., Hoerling, M., Seager, R., Lettenmaier, D., Kumar, A., \& Gutzler, D. (2007). Predicting drought on seasonal-to-decadal time scales. Bulletin of the American Meteorological Society, 88, 1625-1630.

Schuol, J., Abbaspour, K.C., Yang, H., Srinivasan, R., \& Zehnder, A.J.B. (2008). Modeling blue and green water availability in Africa. Water Resources Research, 44, W07406.

Scrimshaw, N.S. (1987). The phenomenon of famine. Annual Review of Nutrition, 7, 1-21.

Seaquist, J.W., Hickler, T. Eklundh, L. Ardö, J., \& Heumann, B. (2009). Disentangling the effects of climate and people on sahel vegetation dynamics . Biogeosciences, 6, 469-477.

Shiau, J.T., \& Modarres, R. (2009). Copula-based drought severity-duration-frequency analysis in Iran. Meteorological Applications, 16, 481-489.

Sinclair, D.S., \& Pegram, C.G.S. (2010). A comparison of ASCAT and modeled soil moisture over South Africa, using TOPKAPI in land surface mode. Hydrol. Earth Syst. Sci., 14, 613-626.

Sivakumar M.V.K., Motha R.P., Wilhite D.A., \& Wood D.A. (2010). Agricultural drought indices. Proceedings of an expert meeting, 2-4 June 2010, Murcia, Spain. World Meteorological Organization, Geneva, 219 pp.

Sjöström, M., Ardö, J., Eklundh, L., El-Tahir, B. A., El-Khidir, H. A. M., Hellström, M., Pilesjö, P., \& Seaquist, J. (2009). Evaluation of satellite based indices for gross primary production estimates in a sparse savannah in the Sudan. Biogeosciences, 6, 129-138.

Stringer, L.C., Dyer, J.C., Reed, M.S., Dougill, A.J., Twyman, C., \& Mkwambisi, D. (2009). Adaptations to climate change, drought and desertification: local insights to enhance policy in southern Africa. Environmental Science \& Policy, 12, 748-765.

Svoboda, M. et al. (2002). The drought monitor. Bulletin of the American Meteorological Society, 83, 1181-1190.

Svoboda, M.D., Hayes, M.J., Wilhite, D.A., \& Tadesse, T. (2004). Recent advances in drought monitoring. Bulletin of the American Meteorological Society, 5237-5240. 
Szalai, S., Szinell, C.S., \& Zoboki, J. (2000). Drought monitoring in Hungary. En Early warning systems for drought preparedness and drought management. World Meteorological Organization. Lisbon: 182-199.

Tarhule, A., \& Lamb, P.J. (2003). Climate research and seasonal forecasting for West Africans. Bulletin of the American Meteorological Society, 84, 1741-1759.

Thomson, M.C., Doblas-Reyes, F.J., Mason, S.J., Hagedorn, R., Connor, S.J., Phindela, T., Morse, A.P., \& Palmer, T.N. (2006). Malaria early warnings based on seasonal climate forecasts from multi-model ensembles. Nature, 439, 576-579.

Tippett, M.K., \& Barnston, A.G. (2008). Skill of multimodel ENSO probability forecasts. Monthly Weather Review, 136, 3933-3946.

Tucker, C.J., Vanpraet, C., Boerwinkel, E., \& Gaton, A. (1983). Satellite remote sensing of total dry matter accummulation in winter wheat. Remote Sensing of Environment, 11, 171-189.

Tucker, C.J., Newcomb, W.W., Los, S.O., \& Prince, S.D. (1991). Mean and inter-year variation of growing-season normalized difference vegetation index for the Sahel. 1981-1989, International Journal of Remote Sensing, 16, 1133-1135.

Twomlow, S., Mugabe, F.T., Mwale, M., Delve, R., Nanja, D., Carberry, P., \& Howden, M. (2008). Building adaptive capacity to cope with increasing vulnerability due to climatic change in Africa - A new approach. Physics and Chemistry of the Earth, 33, 780-787.

UN, (2008). Trends in sustainable development. Agriculture, rural development, land, desertification and drought. Department of Economic and Social Affairs. United Nations. New York.

Vicente-Serrano, S.M., \& Beguería, S. (2003). Estimating extreme dry-spell risk in the middle Ebro valley (Northeastern Spain): A comparative analysis of partial duration series with a General Pareto distribution and Annual maxima series with a Gumbel distribution. International Journal of Climatology, 23, 1103-1118. 
Vicente-Serrano, S.M., González-Hidalgo, J.C., de Luis, M., \& Raventós, J. (2004). Spatial and temporal patterns of droughts in the Mediterranean area: the Valencia region (East-Spain). Climate Research, 26, 5-15.

Vicente-Serrano, S.M., \& López-Moreno, J.I. (2005). Hydrological response to different time scales of climatological drought: an evaluation of the standardized precipitation index in a mountainous Mediterranean basin. Hydrology and Earth System Sciences, 9, 523-533.

Vicente-Serrano, S.M., Cuadrat, J.M., \& Romo, A. (2006). Early prediction of crop productions using drought indices at different time scales and remote sensing data: application in the Ebro valley (North-east Spain). International Journal of Remote Sensing, 27, 511-518.

Vicente-Serrano, S.M. (2007). Evaluating The Impact Of Drought Using Remote Sensing In A Mediterranean, Semi-Arid Region, Natural Hazards, 40, 173-208.

Vicente-Serrano, S.M., Beguería, S., López-Moreno, J.I., Angulo, M., \& El Kenawy, A. (2010). A new global $0.5^{\circ}$ gridded dataset (1901-2006) of a multiscalar drought index: comparison with current drought index datasets based on the Palmer Drought Severity Index. Journal of Hydrometeorology, 11, 1033-1043

Vicente-Serrano S.M., Beguería, S., \& López-Moreno, J.I. (2010). A Multi-scalar drought index sensitive to global warming: The Standardized Precipitation Evapotranspiration Index SPEI. Journal of Climate, 23, 1696-1718.

Vicente-Serrano, S.M., Beguería, S., \& López-Moreno, J.I. (2011). Comment on "Characteristics and trends in various forms of the Palmer Drought Severity Index (PDSI) during 19002008” by A. Dai. Journal of Geophysical Research-Atmosphere, 116, D19112, doi:10.1029/2011JD016410

Vicente-Serrano, S.M., López-Moreno, J.I., Beguería, S., Lorenzo-Lacruz, J., Azorin-Molina, C., \& Morán-Tejeda, E. (2011b). Accurate computation of a streamflow drought index. Journal of Hydrologic Engineering doi:10.1061/(ASCE)HE.1943-5584.0000433 
Vicente-Serrano, S.M., López-Moreno, J.I., Gimeno, L., Nieto, R., Morán-Tejeda, E., LorenzoLacruz, J., Beguería, S., \& Azorin-Molina, C., (2011c). A multi-scalar global evaluation of the impact of ENSO on droughts. Journal of Geophysical Research-Atmosphere, 116, D20109, doi:10.1029/2011JD016039

Vidal, J.-P., Martin, E., Franchistéguy, L., Habets, F., Soubeyroux, J.-M., Blanchard, M., \& Baillon, M. (2010). Multilevel and multiscale drought reanalysis over France with the Safran-IsbaModcou hydrometeorological suite. Hydrology and Earth System Sciences, 14, 459-478.

Vörösmarty, C.J., Douglas, E.M., Green, P.A., \& Revenga, C. (2005). Geospatial indicators of emerging water stress: An application to Africa. Ambio, 34, 230-236.

Webster, P.J, \& Yang, S. (1992). Monsoon and ENSO: Selectively interactive systems. Quarterly Journal of the Royal Meteorological Society, 118, 877-926.

Wilhite D.A., \& Glantz, M.H. (1985). Understanding the drought phenomenon: the role of definitions. Water International, 10, 111-120.

Wilhite, D.A. (1993). Drought assessment, management and planning: Theory and case studies. Kluwer. Boston.

Wilhite, D.A. (1996). A methodology for drought preparedness. Natural Hazards, 13, 229-252.

Wilhite, D.A., \& Svoboda, M.D. (2000). Drought early warning systems in the context of drought preparedness and mitigation. In Early warning systems for drought preparedness and drought management. World Meteorological Organization. Lisboa: 1-21.

Wilhite, D.A. (2002). Combating drought through preparedness. Natural Resources Forum, 26, $275-285$.

World Bank, (2005): Natural disasters hotspots: A global risk analysis. Disaster Risk Management Series, $\mathrm{n}^{\circ}$ 5. The World Bank. 
Zhao, M., Heinsch, F.A., Nemani, R.R., \& Running, S.W. (2005). Improvements of the modis terrestrial gross and net primary production global data set. Remote Sensing of Environment, $95,164-176$.

Zhao, M., \& Running, S.W. (2010). Drought-induced reduction in global terrestrial net primary production from 2000 through 2009. Science, 329, 940-943. 
To know the relation between drought Determine the atmospheric causes of drought in Africa and climate change

Develop drought indicators sensitive to global warming Perform drought hazard assessment.

Compile a data base of past drought events in Africa.

To improve forecasting methods, Determine the most appropriate drought indicators and time thresholds identification and drought scales to identify drought impacts.

indicators

Develop drought vulnerability curves of natural ecosystems, hydrological systems and agriculture in Africa.

Identify drought impact thresholds for vulnerability analysis.

Assess seasonal drought forecasting methods and develop a drought forecasting model.

Identify vulnerable regions

Perform a spatial drought hazard and vulnerability analysis for the whole African continent.

Develop monitoring capacities and drought observation networks at

Assess current data sources and implement a real-time data various scales acquisition and integration system.

Implement a drought monitoring system.

To improve early warning and forecasting systems and to provide

Assess seasonal drought forecasting and develop a drought credible and timely information for better decision making and forecasting method.

Implement early warning and forecasting systems.

Undertake specific capacity building actions on using real-time preparedness of affected regions and population.

drought information for decision making.

Maintain a forum to ensuring effective uptake of the project outcomes by the end-users.

To strengthen preparedness and planning capacities

To improve capacity building
Produce information (drought hazard and vulnerability maps) for helping in planning for drought risk management

Analyze current formal and informal setups for drought risk management in Africa, with special emphasis on the technical capacities and the use of information on decision making. Organize specific capacity building activities and maintain contact with stakeholders and end-users in the case studies.

Table 1. Open questions that remains unsolved in terms of improving drought mitigation in Africa. 


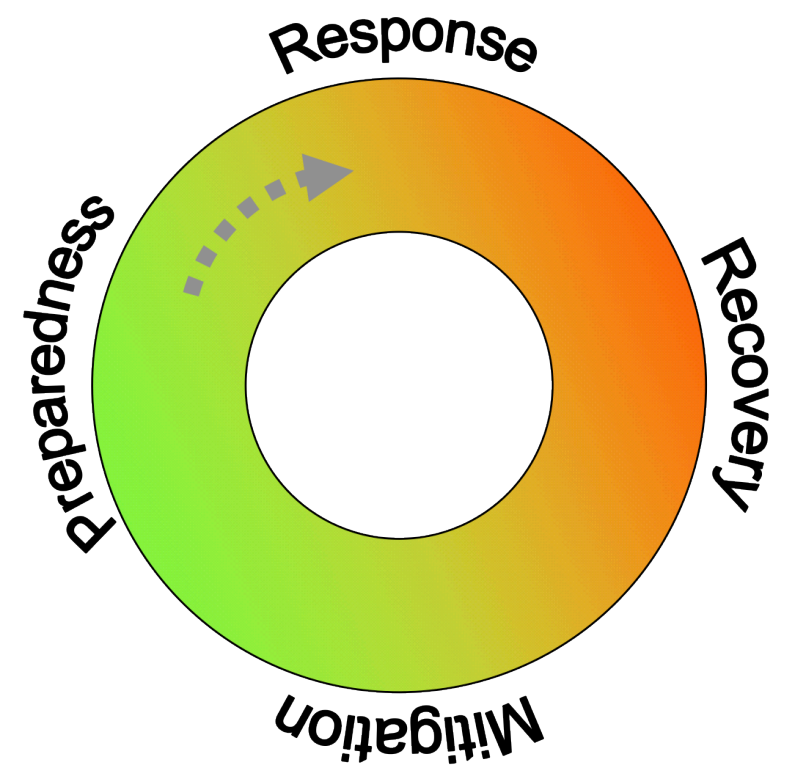

Figure 1. The disaster management cycle. 

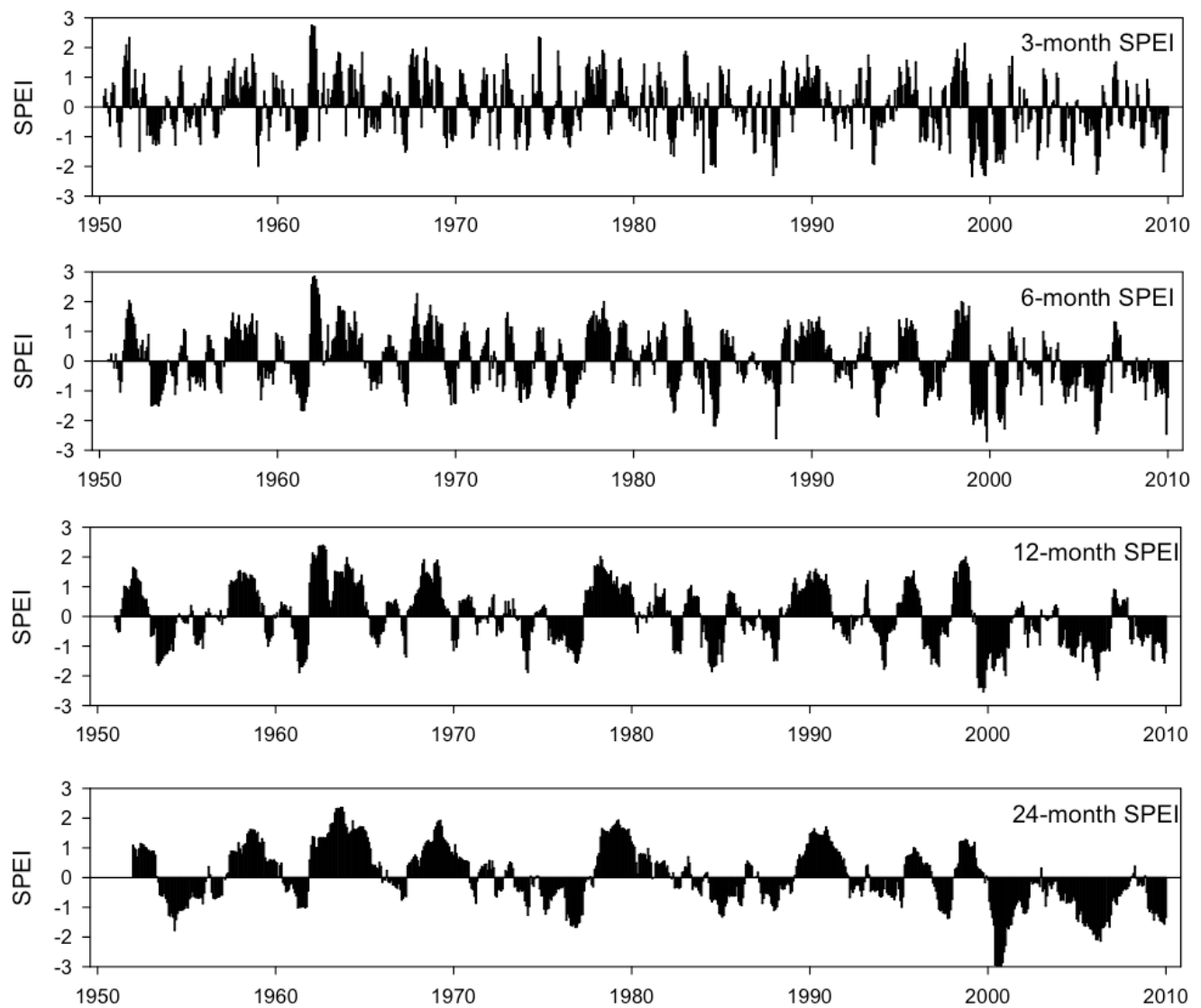

Figure2. Evolution of the Standardized Precipitation Evapotranspiration Index between 1950 and 2011 at Nairobi (Kenya). $1.25^{\circ} \mathrm{S}, 36.7^{\circ} \mathrm{E}$. 

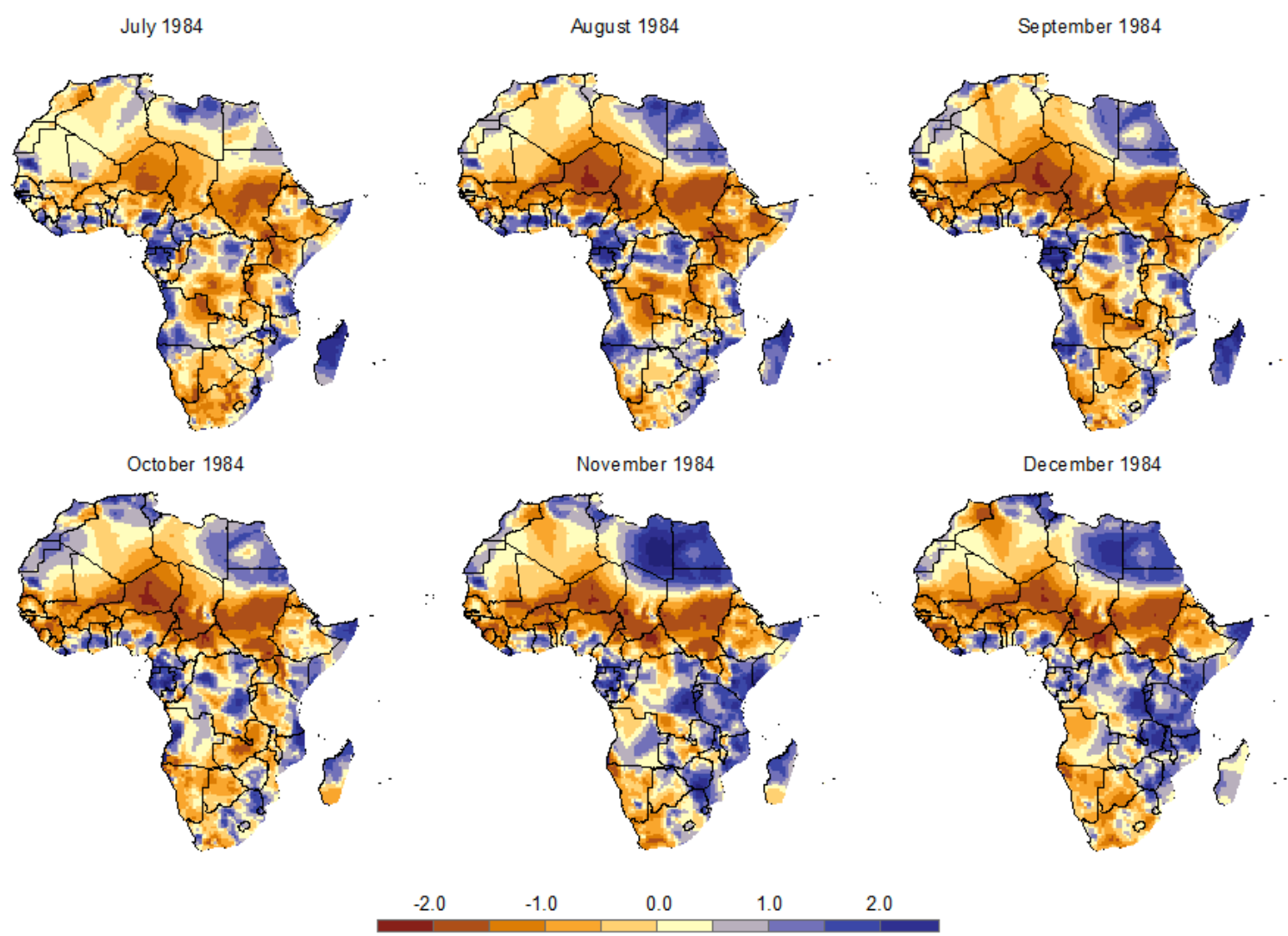

Figure 3. Spatial distribution of the 6-month SPEI for the entire Africa between July and December 1984. 


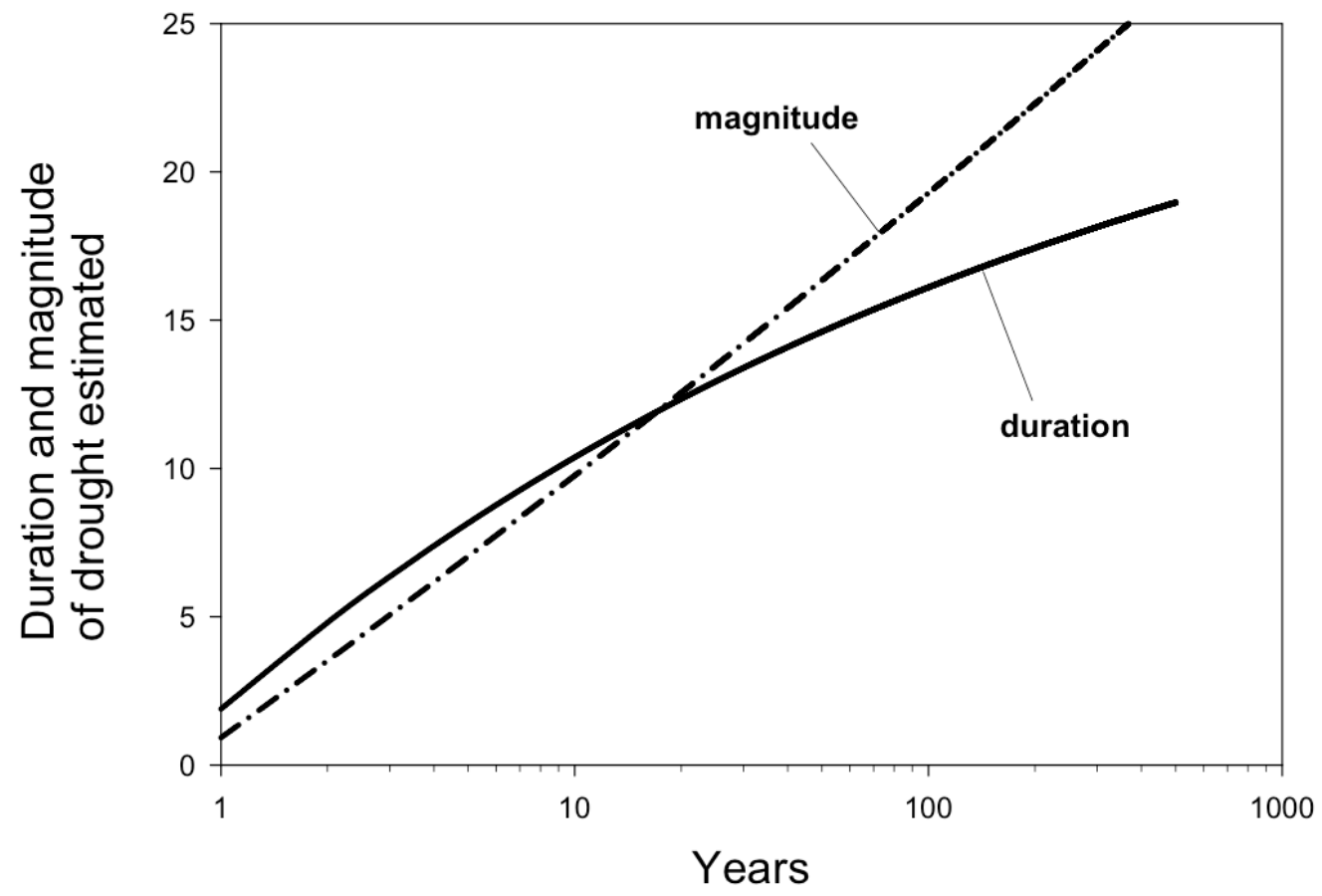

Figure 4. Maximum drought duration (in months) and magnitude (in SPEI units) expected in a period of $\mathrm{n}$ years according at Nairobi (Kenya) using data from 1950 to 2011. 


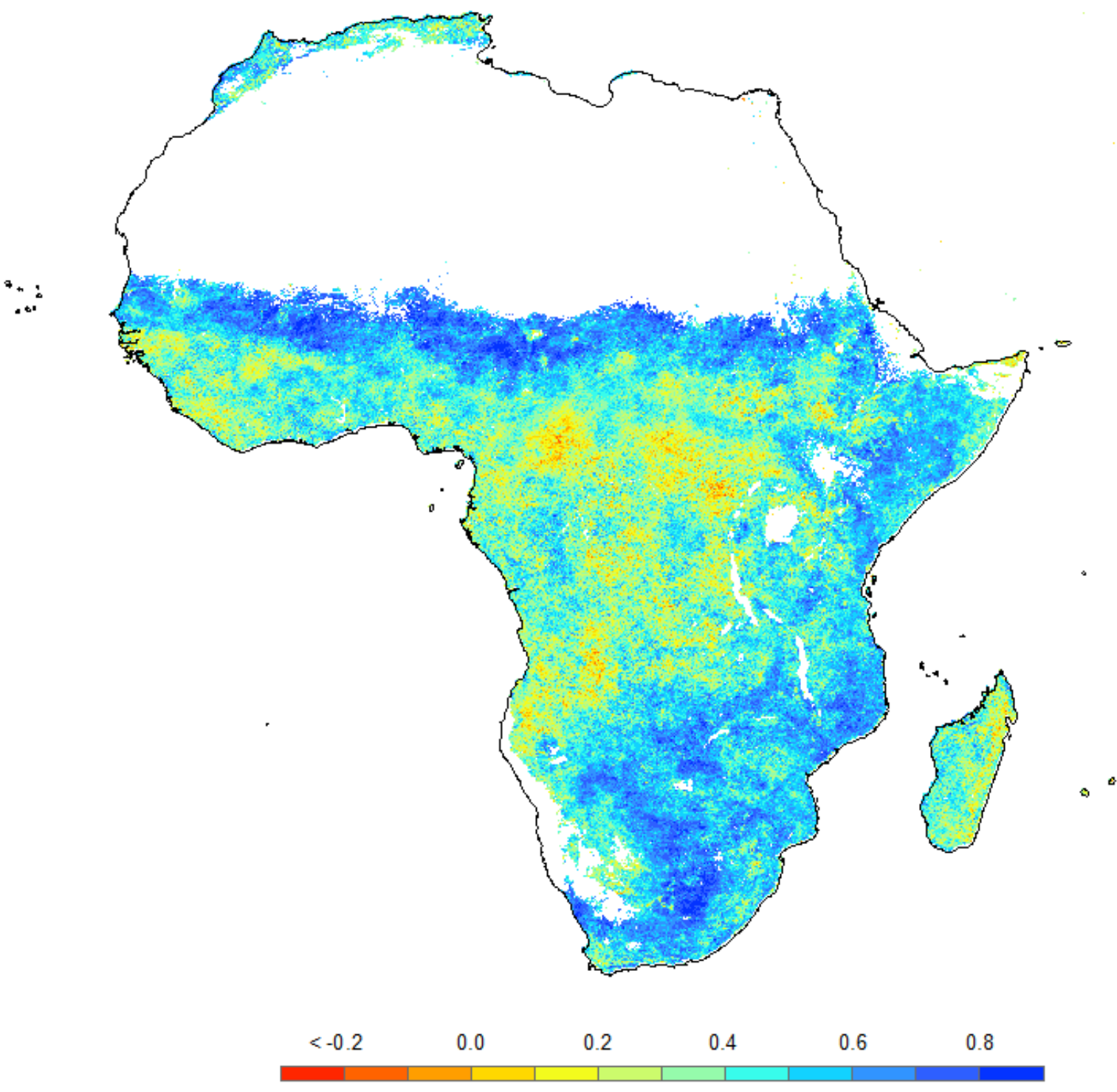

Figure 5. Assessment of drought vulnerability using EO data and drought indices. The figure represents correlation coefficients between the SPEI and the boreal fall NDVI (SeptemberNovember) obtained from NOAA-AVHRR satellites between 1982 and 2006. 

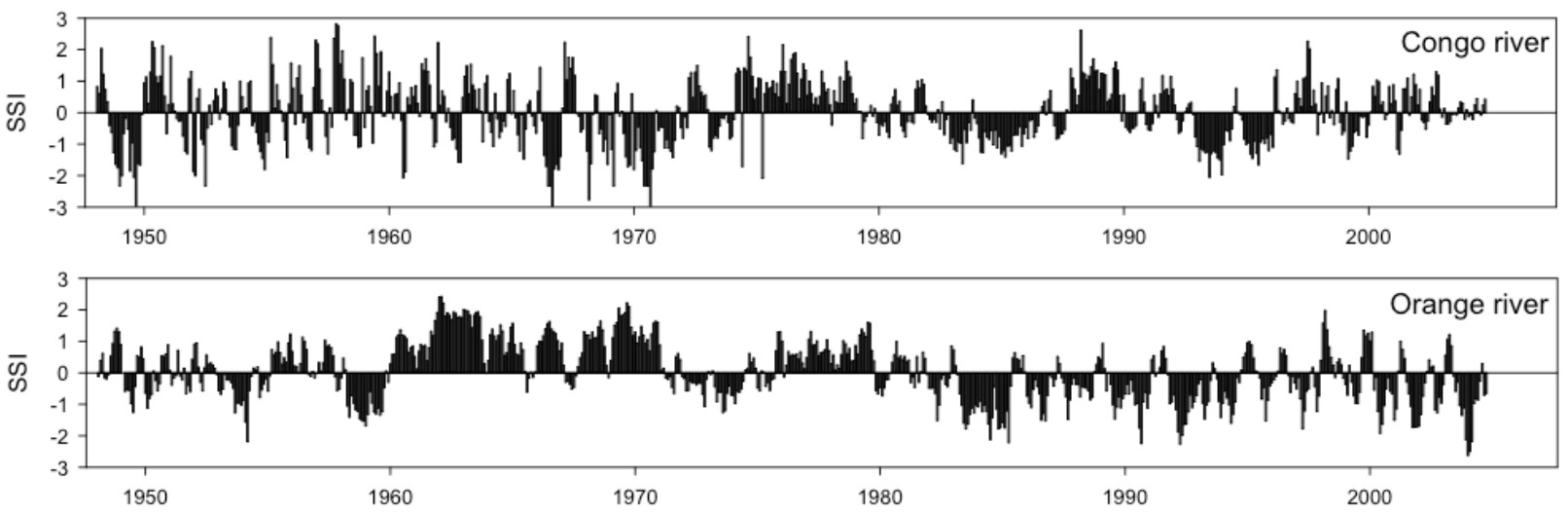

Figure 6: Evolution of the Standardized Streamflow Index (SSI) in the Congo and Orange rivers between 1948 and 2004 

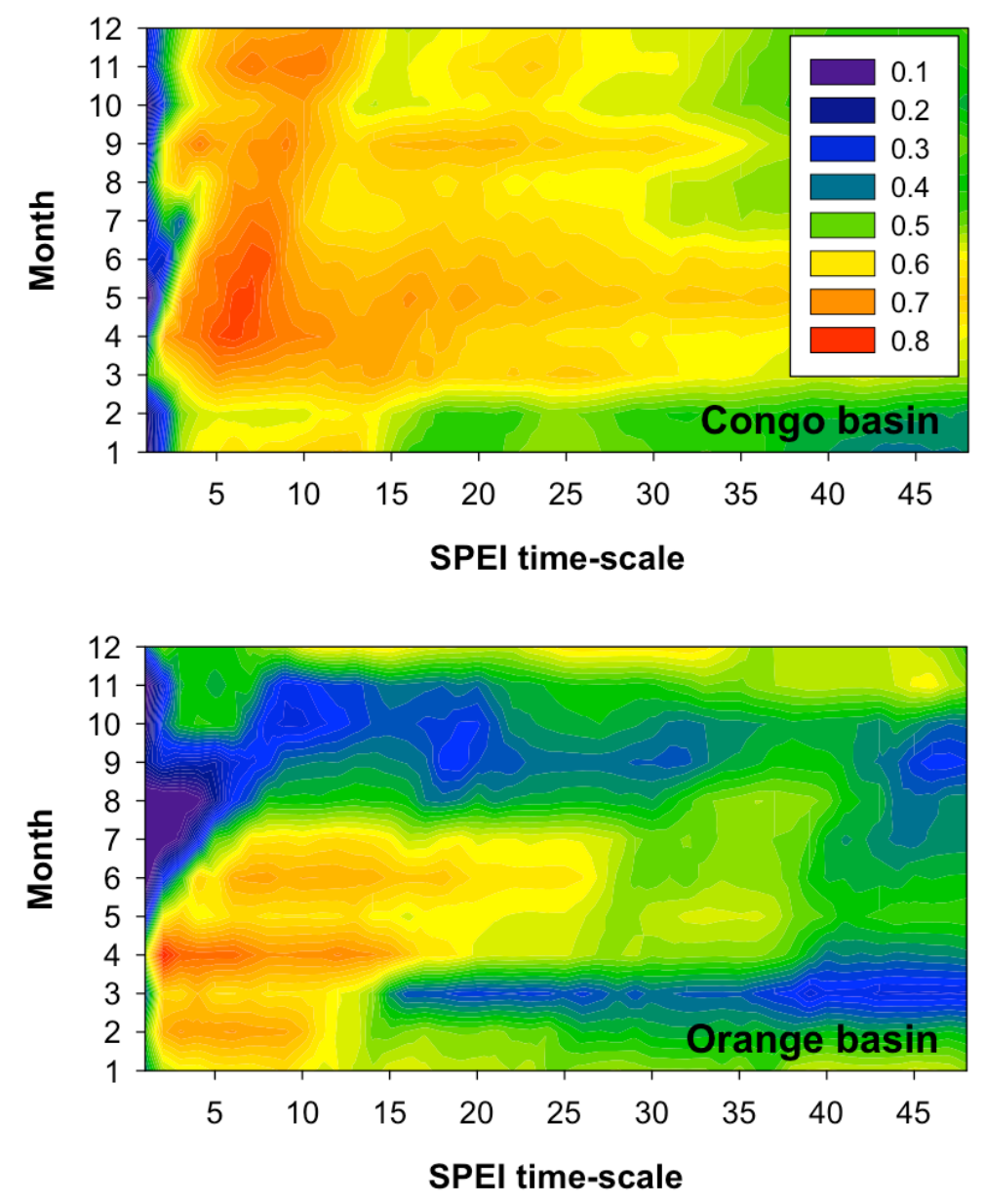

Figure 7: Correlations between the Standardized Streamflow Index (SSI) and the 1- to 48-month SPEI in the Congo and Orange basins between 1948 and 2004 


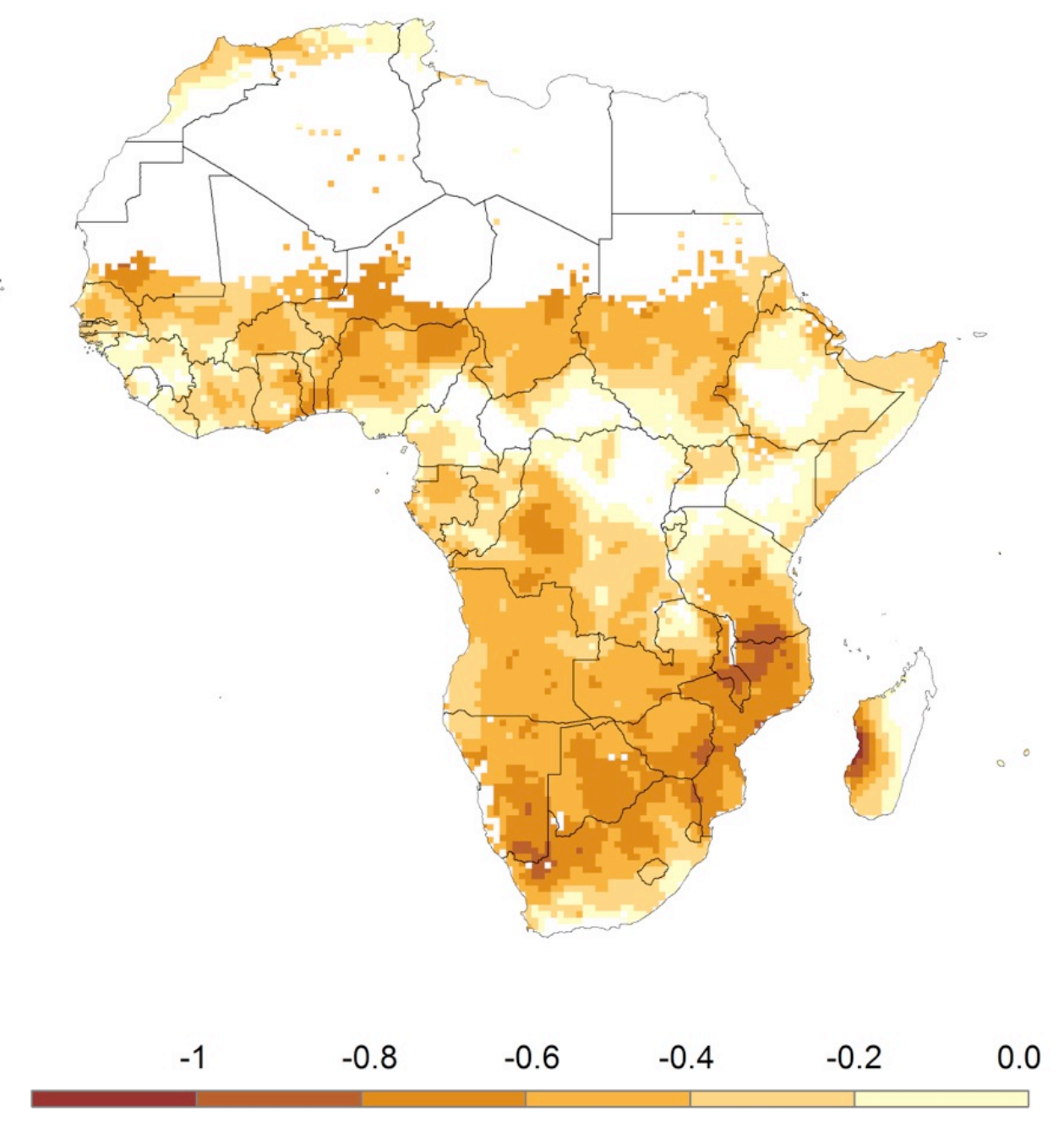

Figure 8: Average 6-month SPEI for August if the years in which an El Niño episode is recorded. Legend is in SPEI units. 